\title{
Dietary Patterns and Neurocognitive Health: A Systematic Review
}

\section{Dietary Guidelines Advisory Committee, Dietary Patterns Subcommittee \\ Published date: July 15, 2020}

Nutrition Evidence Systematic Review

Center for Nutrition Policy and Promotion

Food and Nutrition Service

U.S. Department of Agriculture

Braddock Metro Center II

1320 Braddock Place

Alexandria, Virginia 22314 
This systematic review was conducted by the 2020 Dietary Guidelines Advisory Committee in collaboration with the Nutrition Evidence Systematic Review (NESR) team at the Center for Nutrition Policy and Promotion, Food and Nutrition Service, U.S. Department of Agriculture (USDA). All systematic reviews from the 2020 Advisory Committee Project are available on the NESR website: https://nesr.usda.gov/2020-dietaryguidelines-advisory-committee-systematic-reviews.

Conclusion statements drawn as part of this systematic review describe the state of science related to the specific question examined. Conclusion statements do not draw implications, and should not be interpreted as dietary guidance. This portfolio provides the complete documentation for this systematic review. A summary of this review is included in the 2020 Advisory Committee's Scientific Report available at www.DietaryGuidelines.gov.

The contents of this document may be used and reprinted without permission. Endorsements by NESR, the Center for Nutrition Policy and Promotion, the Food and Nutrition Service, or the USDA of derivative products developed from this work may not be stated or implied.

Suggested citation for this systematic review: 2020 Dietary Guidelines Advisory Committee and Nutrition Evidence Systematic Review Team. Dietary Patterns and Neurocognitive Health: A Systematic Review. 2020 Dietary Guidelines Advisory Committee Project. Alexandria, VA: U.S. Department of Agriculture, Food and Nutrition Service, Center for Nutrition Policy and Promotion, July 2020. Available at: https://nesr.usda.gov/2020-dietary-guidelines-advisory-committee-systematic-reviews.

Related citation: Dietary Guidelines Advisory Committee. 2020. Scientific Report of the 2020 Dietary Guidelines Advisory Committee: Advisory Report to the Secretary of Agriculture and the Secretary of Health and Human Services. U.S. Department of Agriculture, Agricultural Research Service, Washington, DC.

In accordance with Federal civil rights law and USDA civil rights regulations and policies, the USDA, its Agencies, offices, and employees, and institutions participating in or administering USDA programs are prohibited from discriminating based on race, color, national origin, religion, sex, gender identity (including gender expression), sexual orientation, disability, age, marital status, family/parental status, income derived from a public assistance program, political beliefs, or reprisal or retaliation for prior civil rights activity, in any program or activity conducted or funded by USDA (not all bases apply to all programs). Remedies and complaint filing deadlines vary by program or incident.

Persons with disabilities who require alternative means of communication for program information (e.g., Braille, large print, audiotape, American Sign Language, etc.) should contact the responsible Agency or USDA's TARGET Center at (202) 720-2600 (voice and TTY) or contact USDA through the Federal Relay Service at (800) 877-8339. Additionally, program information may be made available in languages other than English.

To file a program discrimination complaint, complete the USDA Program Discrimination Complaint Form, AD3027, found online at How to File a Program Discrimination Complaint and at any USDA office or write a letter addressed to USDA and provide in the letter all of the information requested in the form. To request a copy of the complaint form, call (866) 632-9992. Submit your completed form or letter to USDA by: (1) mail: U.S. Department of Agriculture, Office of the Assistant Secretary for Civil Rights, 1400 Independence Avenue, SW, Washington, D.C. 20250-9410; (2) fax: (202) 690-7442; or (3) email: program.intake@usda.gov.

USDA is an equal opportunity provider, employer, and lender. 


\section{Dietary Patterns Subcommittee:}

- Carol Boushey, PhD, MPH, RD, University of Hawaii, Subcommittee Chair

- Jamy Ard, MD, Wake Forest School of Medicine

- Lydia Bazzano, MD, PhD, Tulane University and Ochsner Health System

- Steven Heymsfield, MD, Louisiana State University, Pennington Biomedical Research Center

- Elizabeth Mayer-Davis, PhD, RD, University of North Carolina at Chapel Hill

- Joan Sabaté, MD, DrPH, Loma Linda University

- Linda Snetselaar, PhD, RDN, University of lowa

- Linda Van Horn, PhD, RDN, LD, Northwestern University

- Barbara Schneeman, PhD, University of California, Davis, Chair of the 2020 Dietary Guidelines Advisory Committee

\section{Nutrition Evidence Systematic Review (NESR) Team:}

- Laural Kelly English, PhD, Analyst, Panum Group ${ }^{i}$

- Marlana Bates, MPH, RD, Analyst, Panum Group ${ }^{i}$

- Emily Callahan, MS, Analyst, Office of Nutrition Guidance and Analysis (ONGA), Center for Nutrition Policy and Promotion (CNPP), Food and Nutrition Service (FNS), U.S. Department of Agriculture (USDA)

- Sudha Venkatramanan, PhD, Analyst, Panum Groupi

- Gisela Butera, MLIS, MEd, Systematic Review Librarian, Panum Groupi

- Nancy Terry, MS, MLS, Biomedical Librarian, National Institutes of Health (NIH) Library, U.S. Department of Health and Human Services (HHS)

- Julie Obbagy, PhD, RD, Project Lead, ONGA, CNPP, FNS, USDA

\section{Federal Liaisons:}

- Elizabeth Rahavi, RD, ONGA, CNPP, FNS, USDA

- Clarissa (Claire) Brown, MS, MPH, RD, ONGA, CNPP, FNS, USDA

\section{Project Leadership:}

- Eve Essery Stoody, PhD, Designated Federal Officer and Director, ONGA, CNPP, FNS, USDA

- Janet de Jesus, MS, RD, Nutrition Advisor, Office of Disease Prevention and Health Promotion, Office of the Assistant Secretary for Health, HHS

USDA and HHS implemented a process to identify topics and scientific questions to be examined by the 2020 Dietary Guidelines Advisory Committee. The Committee conducted its review of evidence in subcommittees for discussion by the full Committee during its public meetings. The role of the Committee members involved establishing all aspects of the protocol, which presented the plan for how they would examine the scientific evidence, including the inclusion and exclusion criteria; reviewing all studies that met the criteria they set; deliberating on the body of evidence

\footnotetext{
i Under contract with the Food and Nutrition Service, United States Department of Agriculture.
} 
for each question; and writing and grading the conclusion statements to be included in the scientific report the 2020 Committee submitted to USDA and HHS. The NESR team with assistance from Federal Liaisons and Project Leadership, supported the Committee by facilitating, executing, and documenting the work necessary to ensure the reviews were completed in accordance with NESR methodology. More information about the 2020 Dietary Guidelines Advisory Committee, including the process used to identify topics and questions, can be found at www.DietaryGuidelines.gov. More information about NESR can be found at NESR.usda.gov.

The Committee and NESR staff thank USDA's Agricultural Research Service for coordinating the peer review of this systematic review, and the Federal scientist peer reviewers for their time and expertise.

FUNDING SOURCE: United States Department of Agriculture, Food and Nutrition Service, Center for Nutrition Policy and Promotion, Alexandria, VA 


\section{TABLE OF CONTENTS}

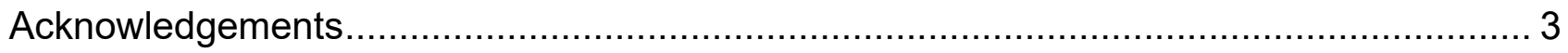

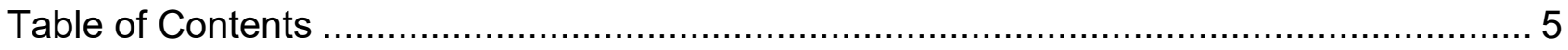

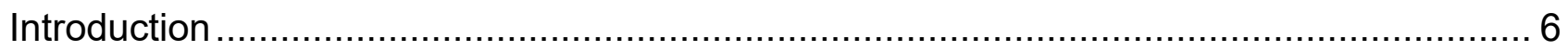

What is the relationship between dietary patterns consumed and neurocognitive health? .. 9

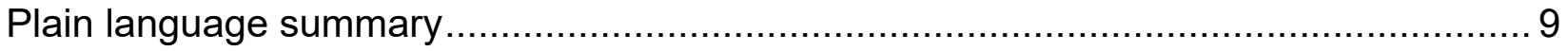

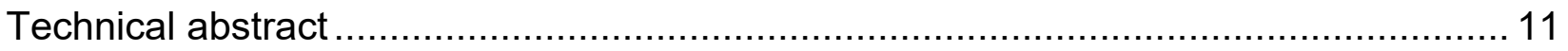

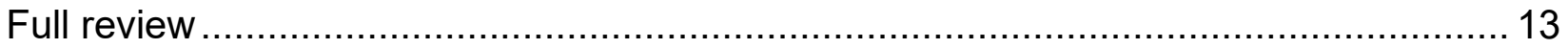

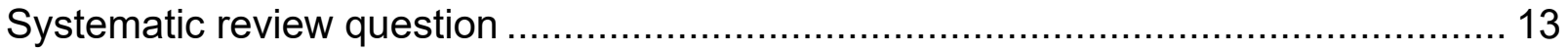

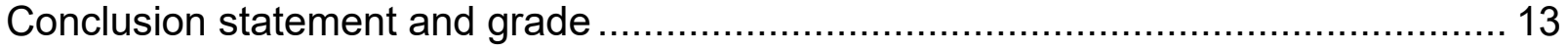

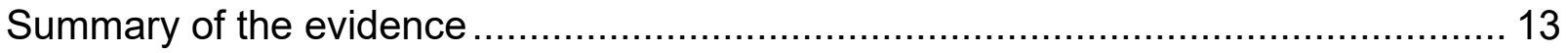

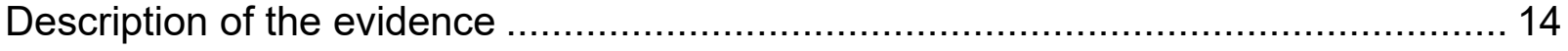

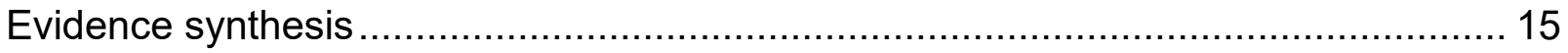

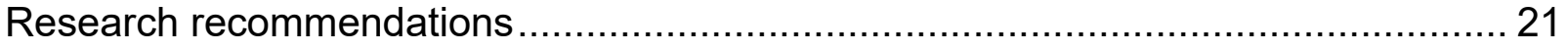

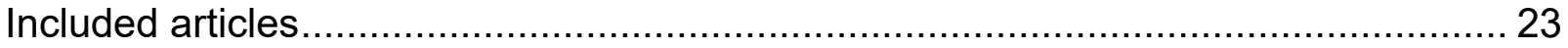

Methodology

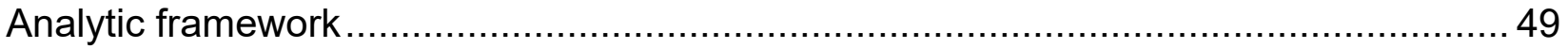

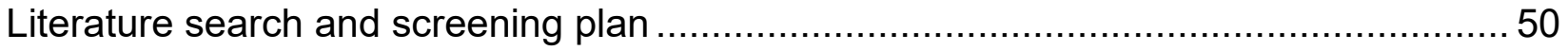

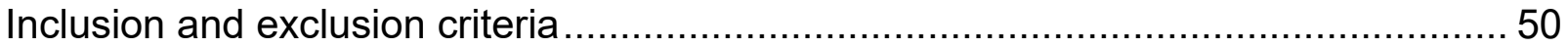

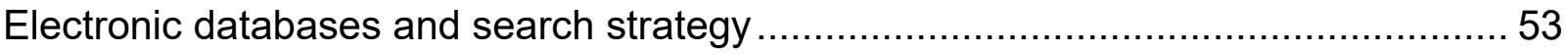

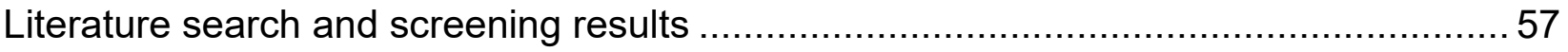

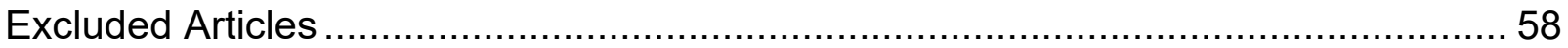

Table 1: Description of randomized controlled trials that examined the relationship between dietary patterns and cognitive impairment, dementia, or Alzheimer's disease ................... 25 Table 2: Description of observational studies that examined the relationship between dietary patterns and cognitive impairment, dementia, or Alzheimer's disease ................... 28 Table 3. Risk of bias for randomized controlled trials examining dietary patterns and cognitive impairment, dementia, or Alzheimer's disease.

Table 4. Risk of bias for observational studies examining dietary patterns and cognitive

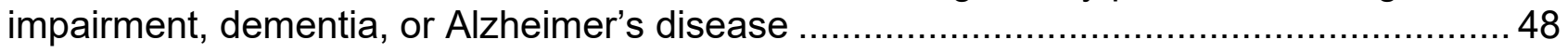

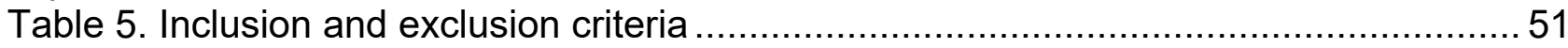

Table 6. Articles excluded after full text screening with rationale for exclusion..................58

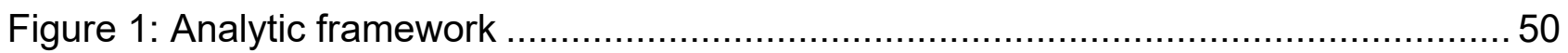

Figure 2: Flow chart of literature search and screening results..................................... 57 
This document describes a systematic review conducted to answer the following question: What is the relationship between dietary patterns consumed and neurocognitive health? This systematic review was conducted by the 2020 Dietary Guidelines Advisory Committee, supported by USDA's Nutrition Evidence Systematic Review (NESR).

More information about the 2020 Dietary Guidelines Advisory Committee is available at the following website: www.DietaryGuidelines.gov.

NESR specializes in conducting food- and nutrition-related systematic reviews using a rigorous, protocol-driven methodology. More information about NESR is available at the following website: https://NESR.usda.gov.

NESR's systematic review methodology involves developing a protocol, searching for and selecting studies, extracting data from and assessing the risk of bias of each included study, synthesizing the evidence, developing conclusion statements, grading the evidence underlying the conclusion statements, and recommending future research. A detailed description of the systematic reviews conducted for the 2020 Dietary Guidelines Advisory Committee, including information about methodology, is available on the NESR website: https://nesr.usda.gov/2020-dietary-guidelines-advisory-committee-systematic-reviews. In addition, starting on page 49 , this document describes the final protocol as it was applied in the systematic review. A description of and rationale for modifications made to the protocol are described in the 2020 Dietary Guidelines Advisory Committee Report, Part D: Chapter 8. Dietary Patterns. 


\section{List of abbreviations}

\begin{tabular}{|c|c|}
\hline Abbreviation & Full name \\
\hline AHEI-2010 & Alternative Healthy Eating Index-2010 \\
\hline aMED & Alternate Mediterranean diet score \\
\hline A-MeDi & Alternate Mediterranean diet \\
\hline APDQS & A Priori Diet Quality Score \\
\hline BSD & Baltic Sea Diet \\
\hline CERAD & Consortium to Establish a Registry for Alzheimer's Disease \\
\hline CVD & Cardiovascular disease \\
\hline DASH & Dietary Approaches to Stop Hypertension \\
\hline HHS & United States Department of Health and Human Services \\
\hline EVOO & Extra virgin olive oil \\
\hline FFQ & Food frequency questionnaire \\
\hline HEI-2010 & Healthy Eating Index-2010 \\
\hline HHS & Health and Human Services \\
\hline hPDI & Healthful plant-based diet index \\
\hline MIND & Mediterranean-DASH diet Intervention for Neurodegenerative Delay \\
\hline MMSE & Mini-Mental State Examiniation \\
\hline mo & Month(s) \\
\hline MUFA & Monounsaturated fatty acids \\
\hline NESR & Nutrition Evidence Systematic Review \\
\hline NHLBI & National Heart, Lung, and Blood Institute \\
\hline $\mathrm{NIH}$ & National Institutes of Health \\
\hline PDI & Plant-based diet index \\
\hline PUFA & Polyunsaturated fatty acids \\
\hline $\mathrm{RCT}$ & Randomized controlled trial \\
\hline RRR & Reduced rank regression \\
\hline SF-EMSE & Short Form Extended Mental State Exam \\
\hline
\end{tabular}




\begin{tabular}{ll}
\hline Abbreviation & Full name \\
\hline USDA & United States Department of Agriculture \\
\hline WHI & Women's Health Initiative \\
\hline wk & Week(s) \\
\hline y & Year(s) \\
\hline
\end{tabular}




\section{WHAT IS THE RELATIONSHIP BETWEEN DIETARY PATTERNS CONSUMED AND NEUROCOGNITIVE HEALTH?}

\section{PLAIN LANGUAGE SUMMARY}

\section{What is the question?}

- The question is: What is the relationship between dietary patterns consumed and neurocognitive health?

What is the answer to the question?

- Limited evidence suggests that dietary patterns containing vegetables, fruits, unsaturated vegetable oils and/or nuts, legumes, and fish or seafood consumed during adulthood are associated with lower risk of age-related cognitive impairment and/or dementia.

Why was this question asked?

- This important public health question was identified by the U.S. Departments of Agriculture (USDA) and Health and Human Services (HHS) to be examined by the 2020 Dietary Guidelines Advisory Committee.

How was this question answered?

- The 2020 Dietary Guidelines Advisory Committee, Dietary Patterns Subcommittee conducted a systematic review to answer this question with support from the Nutrition Evidence Systematic Review (NESR) team.

- Dietary patterns were defined as the quantities, proportions, variety, or combination of different foods, drinks, and nutrients (when available) in diets, and the frequency with which they are habitually consumed.

\section{What is the population of interest?}

- For the intervention/exposure, children through older adults, age 2 years and older

- For the outcome, adults and older adults, age 19 years and older

\section{What evidence was found?}

- This review identified 26 articles that met inclusion criteria.

- Most studies reported dietary patterns consumed during adulthood relate to improved cognitive measures or lower risk of cognitive impairment. These dietary patterns were higher in vegetables, fruits, unsaturated vegetable oils and/or nuts, legumes, and fish or seafood.

- Many limitations in study design and conduct were identified in the included studies. This includes differences in dietary patterns examined, cognitive assessment methods, and lack of accounting for possible changes in diet over time.

- The 2020 Committee updates and builds on the conclusion drawn by the 2015 Committee from an existing systematic review.

How up-to-date is this systematic review?

- This review searched for studies published from January 2014 to February 2020, and updated an existing systematic review that included evidence from January 
1980 to August 2014. 


\section{TECHNICAL ABSTRACT}

\section{Background}

- This important public health question was identified by the U.S. Departments of Agriculture (USDA) and Health and Human Services (HHS) to be examined by the 2020 Dietary Guidelines Advisory Committee.

- The 2020 Dietary Guidelines Advisory Committee, Dietary Patterns Subcommittee conducted a systematic review to answer this question with support from the Nutrition Evidence Systematic Review (NESR) team.

- The goal of this systematic review was to examine the following question: What is the relationship between dietary patterns consumed and neurocognitive health?

\section{Conclusion statement and grade}

- Limited evidence suggests that dietary patterns containing vegetables, fruits, unsaturated vegetable oils and/or nuts, legumes, and fish or seafood consumed during adulthood are associated with lower risk of age-related cognitive impairment and/or dementia. (Grade: Limited)

\section{Methods}

- Two literature searches were conducted using 3 databases (PubMed, Cochrane, Embase) to identify articles that evaluated the intervention or exposure of dietary patterns consumed and the outcomes of neurocognitive health. A manual search was conducted to identify articles that may not have been included in the electronic databases searched. Articles were screened by two NESR analysts independently for inclusion based on pre-determined criteria

- Data extraction and risk of bias assessment were conducted for each included study, and both were checked for accuracy. The Committee qualitatively synthesized the body of evidence to inform development of a conclusion statement(s), and graded the strength of evidence using pre-established criteria for risk of bias, consistency, directness, precision, and generalizability.

- Dietary patterns were defined as the quantities, proportions, variety, or combination of different foods, drinks, and nutrients (when available) in diets, and the frequency with which they are habitually consumed.

\section{Summary of the evidence}

- This systematic review update includes 26 articles that met inclusion criteria and were published between January 2014 and February 2020.

- Four studies were randomized controlled trials.

- Twenty-two articles were from observational studies, with 21 prospective cohort designs and 1 nested-case control design.

- Studies in this update to the existing review produced similarly consistent results regarding the relationship between dietary patterns in adults and age-related cognitive decline, mild cognitive impairment, and/or dementia

- Dietary patterns were examined using various approaches including 17 studies that examined adherence to a dietary pattern using indices/scores, 4 articles identified dietary patterns using factor/cluster analysis, and 1 study used reduced rank regression.

- Outcomes were measured using various approaches and reported as global 
cognition, cognitive performance, mild cognitive impairment, and/or incident dementia.

- The majority of significant findings reported dietary patterns consumed during adulthood were "protective" in either improving measures of cognitive impairment and/or reducing risk of cognitive impairment or dementia. These protective dietary patterns contained vegetables, fruits, unsaturated vegetable oils and/or nuts, legumes, and fish or seafood. Many of these dietary patterns also emphasized whole grains, non-refined grains, or (non-refined) breads/cereals.

- Not all of these protective dietary patterns contained alcoholic beverages. The benefit of the overall dietary pattern with the outcome was still observed if alcoholic beverages, particularly red wine, were included.

- Non-significant findings or those reporting mixed associations reported dietary patterns consumed during adulthood did not worsen cognitive outcomes.

- There are numerous limitations across the body of evidence, including the lack of RCT's, considerable variation in testing methods used, validity and reliability of the methods used, the dietary patterns and cognitive outcomes examined.

- This body of evidence updates and builds upon the conclusion drawn by the 2015 Dietary Guidelines Advisory Committee in an existing systematic review, which consisted of 30 articles from a wide range of study designs that used different methods to measure neurocognitive outcomes but produced relatively consistent findings. 


\section{FULL REVIEW}

\section{Systematic review question}

What is the relationship between dietary patterns consumed and neurocognitive health?

\section{Conclusion statement and grade}

Limited evidence suggests that dietary patterns containing vegetables, fruits, unsaturated vegetable oils and/or nuts, legumes, and fish or seafood consumed during adulthood are associated with lower risk of age-related cognitive impairment and/or dementia. (Grade: Limited)

\section{Summary of the evidence}

- This systematic review update includes 26 articles that met inclusion criteria and were published between January 2014 and February 2020.

- Four studies were randomized controlled trials. ${ }^{1-4}$

- Twenty-two articles were from observational studies, with 21 prospective cohort designs and 1 nested-case control design. ${ }^{5-26}$

- This body of evidence updates and builds upon the existing systematic review, which consisted of 30 articles from a wide range of study designs that used different methods to measure neurocognitive outcomes but produced relatively consistent findings.

- Dietary patterns were defined as the quantities, proportions, variety, or combination of different foods, drinks, and nutrients (when available) in diets, and the frequency with which they are habitually consumed.

- Studies in this update to the existing review produced similarly consistent results regarding the relationship between dietary patterns in adults and agerelated cognitive decline, mild cognitive impairment, and/or dementia

- Dietary patterns were examined using various approaches including 17 studies that examined adherence to a dietary pattern using indices/scores, 4 articles identified dietary patterns using factor/cluster analysis, and 1 study used reduced rank regression.

- Outcomes were measured using various approaches and reported as global cognition, cognitive performance, mild cognitive impairment, and/or incident dementia.

- The majority of significant findings reported dietary patterns consumed during adulthood were "protective" in either improving measures of cognitive impairment and/or reducing risk of cognitive impairment or dementia. These protective dietary patterns contained vegetables, fruits, unsaturated vegetable oils and/or nuts, legumes, and fish or seafood. Many of these dietary patterns also emphasized whole grains, non-refined grains, or (nonrefined) breads/cereals.

- Not all of these protective dietary patterns contained alcoholic beverages. The benefit of the overall dietary pattern with the outcome was still observed if alcoholic beverages, particularly red wine, were included. 
- Non-significant findings or those reporting mixed associations reported dietary patterns consumed during adulthood did not worsen cognitive outcomes.

- There are numerous limitations across the body of evidence, including the lack of RCT's, considerable variation in testing methods used, validity and reliability of the methods used, the dietary patterns and cognitive outcomes examined.

- The 2020 Dietary Guidelines Advisory Committee updates, concurs, and builds upon the conclusion drawn by the 2015 Dietary Guidelines Advisory Committee. ${ }^{27}$

\section{Description of the evidence}

This systematic review update includes 26 articles that examined the relationship between dietary patterns and neurocognitive health. Four studies were randomized controlled trials (RCTs) and 22 articles were from observational studies, with 21 prospective cohort designs and 1 nested-case control.

\section{Population/participant characteristics}

The articles examining the relationship between dietary patterns and neurocognitive health were conducted in the following countries:

- Australia

- Finland

- France

- Japan

- Netherlands

- Singapore

- Sweden

- United Kingdom

- United States

Two articles were from studies conducted in participants from several countries: one was conducted in France, Italy, Netherlands, Poland, and United Kingdom ${ }^{2}$ and the other in 40 different countries. ${ }^{21}$ The analytic sample size ranged from 137 to 27,842.

Data from these studies represented several established cohorts, including the Nurses' Health Study (NHS), Health Professionals' Follow-up Study (HPFS), Women's Health Initiative (WHI) Memory study, Atherosclerosis Risk in Communities (ARIC) study, Swedish National study on Aging and Care-Kungsholmen (SNAC-K), Whitehall II cohort, and EPIC-Norfolk. Although multiple articles from the same cohorts were included, the included articles represented unique data by examining different subsamples, dietary patterns, neurocognitive health outcomes, or using different dietary pattern methods.

Studies included participants who were healthy and/or at risk of chronic disease, and primarily middle-aged or older adults. In two studies, baseline age at enrollment was < $30 y .{ }^{13,26}$ Several articles exclusively enrolled women ${ }^{1,7,8,11,24,26}$ or men. ${ }^{9}$ All other studies combined and/or stratified analyses of men and women. Several studies excluded participants with dementia or conditions that may cause cognitive impairment, prevalent chronic diseases (e.g., cancer, CVD) at baseline, or those who reported race other than White or Black. 


\section{Intervention/exposure}

Dietary intake was primarily assessed using validated food frequency questionnaires (FFQs) at one time-point (i.e., baseline). However, several studies collected dietary data at multiple time points, used a cumulative average or mean of multiple time points, or used validated 24-h dietary recalls or history methods.

Dietary patterns were assessed with various methods. Four RCTs assigned participants to consume a particular dietary pattern as an intervention diet relative to control diet groups. Most (17) of the observational studies examined adherence to a dietary pattern using indices/scores, four articles identified dietary patterns using factor/cluster analysis, and one study used reduced rank regression.

\section{Outcome assessment}

Studies examined age-related cognitive impairment, decline, and/or dementia over follow-up (f/u) as short as $3 \mathrm{mo}$ (in RCTs) up to 30y (in observational studies). No studies that met inclusion criteria examined incidence of diagnosed Alzheimer's disease. Among the included studies, cognitive impairment, cognitive function, and/or dementia were reported by studies using a variety of assessment methods including:

- Consortium to Establish a Registry for Alzheimer's Disease (CERAD) Battery

- Mini-Mental State Examiniation (MMSE)

- Telephone Interview for Cognitive Status (TICS), a telephone-adaption of MMSE to assess overall cognitive performance

- Six-item screener (SIS) via telephone

- Short Form Extended Mental State Exam (SF-EMSE)

- Subjective memory complaints (SMCs)

\section{Evidence synthesis}

\section{Description of results}

\section{Randomized controlled trials (RCTs)}

Four RCT's examined the relationship between dietary patterns and cognitive impairment, global cognitive function/decline, or probable dementia that are summarized below and further in Table 1.

- Chlebowski et al ${ }^{1}$ reported from the Women's Health Initiative Memory study that postmenopausal women, $n=1606$, who consumed the intervention diet aimed at reducing total fat to $20 \%$ energy/d, consuming 5 servings/d of fruits and vegetables, and 6 servings/d of grains, compared to the control group, reduced the risk of possible or mild cognitive impairment and probable dementia at $\sim 8.5 \mathrm{y} \mathrm{f} / \mathrm{u}$.

- Effects reported in Marseglia et $\mathrm{al}^{2}$ showed that $\mathrm{n}=1144$ participants with higher vs. lower "Nu-AGE diet", which provided participants with whole grain pasta, margarine rich in poly-unsaturated fatty acids (PUFA) and monounsaturated fatty acids (MUFA), low fat, low-salt cheese, extra virgin olive oil (EVOO) and frozen vegetable soup, had significant improvements in global cognition and episodic memory scores after $1 \mathrm{y}$. However, no significant differences were observed between groups in cognitive domains after $1 \mathrm{y}$.

- Two RCTs examined different versions of a "Mediterranean" diet.

○ Knight et $\mathrm{al}^{3}$ assigned participants to consume a "MedDiet", consisting of: 
EVOO; breads and cereals; legumes; vegetables; fish; fruit; cheese; red wine (upon participants choice, not compulsory); Greek yoghurt; Nuts; potato (white); Milk; eggs provided; "Free foods": legumes, Greek yoghurt, Australian EVOO, canned tuna, walnuts, peanuts, and almonds compared to control group consuming their customary diet. No significant effects were identified, $n=137$, between the "MedDiet" and control diet on better or worse cognitive function after 3 or $6 \mathrm{mo}$.

- Valls-Pedret et $\mathrm{al}^{4}$ examined $\mathrm{n}=334$ participants randomized to consume either a control diet or one of two different Mediterranean diets, with each emphasizing abundant olive oil, vegetables, fresh fruit and juices, legumes, fish or seafood, nuts and seeds, select white meat instead of red or processed meats, cook regularly with tomato, garlic and onion; wine preferred if consuming alcohol; ad libitum nuts, eggs, fish, seafood, low-fat cheese, chocolate, and whole-grain cereals. Each intervention diet differed by the addition of either EVOO (Med+EVOO) or nuts (Med+Nuts), compared to control group consuming their customary diet. Valls-Pedret et $\mathrm{al}^{4}$ reported that participants consuming the Med+EVOO compared to control diets showed significantly better executive function and global cognition. However, participants in the Med+Nuts compared to control diet group showed significant effects for improved memory, but not executive function or global cognition after $\sim 5 \mathrm{y}$.

\section{Observational studies}

Twenty-two observational studies examined the relationship between dietary patterns and age-related cognitive outcomes, including global cognitive decline, risk of cognitive impairment, and/or risk of (probable) dementia. Studies are summarized below and described further in Table 2.

Indices/scores

\section{Dietary Guidelines-related indices/scores}

Studies reported lower risk of cognitive decline/impairment as follows:

- Smyth et $\mathrm{a}^{21}$ reported that extreme quintiles of highest vs. lowest adherence to the Alternative Healthy Eating Index (AHEI) was significantly associated with less cognitive decline during $5 y \mathrm{f} / \mathrm{u}$, both overall and in those with MMSE 26-28 or $>28$ at baseline, as well as those with moderate or high physical activity at baseline.

- Wu et al ${ }^{25}$ reported that higher vs. lower adherence to the AHEI-2010 was significantly associated with lower risk of cognitive impairment at $20 \mathrm{y} / \mathrm{u}$.

Studies reported no significant associations as follows:

- Akbaraly et al ${ }^{6}$ reported that AHEI-2010 score during midlife was not significantly associated with subsequent risk for dementia or cognitive decline during $25 y \mathrm{f} / \mathrm{u}$.

- Haring et al ${ }^{11}$ reported that Healthy Eating Index-2010 (HEI-2010) or AHEI-2010 scores across quintiles were not significantly associated with mild cognitive impairment, probable dementia, or incidence of either at $\sim 9 \mathrm{y} / \mathrm{u}$.

- Richard et al ${ }^{16}$ reported no significant associations between AHEI-2010 adherence and cognitive outcomes. 
Mediterranean related indices/scores

Studies reported lower risk of cognitive decline/impairment as follows:

- Richard et $\mathrm{al}^{16}$ reported that higher vs. lower adherence to the alternative Mediterranean (aMED) score was significantly associated with better cognitive function.

- Bhushan et $\mathrm{al}^{9}$ reported that higher vs. lower Mediterranean dietary pattern adherence is significantly associated prospectively with better cognitive function in men.

- Shannon et $\mathrm{a}^{20}$ reported that higher adherence to three Mediterranean diet (MedDiet) scores was significantly associated with better performance on global cognition during $14 \mathrm{y} / \mathrm{u}$ in middle-aged adults. There was no significant association with the diet scores and other aspects of cognitive performance (i.e., retrospective memory, attention, or complex processing speed). MedDiet pyramid adherence score was significantly associated with better performance in simple processing speed and retrospective memory, but the other two scores were not.

- Shakersain et $\mathrm{al}^{19}$ reported that higher vs. lower adherence (both continuously and categorically) the Mediterranean-DASH diet Intervention for Neurodegenerative Delay (MIND) pattern, and MedDiet score in older adults was significantly associated with less MMSE decline at $6 \mathrm{y} / \mathrm{u}$.

- Wagner et al ${ }^{24}$ reported that cases of cognitive decline compared to controls without had lower adherence to A-MeDi after $1 \mathrm{y} / \mathrm{u}$.

- Wu et $a^{25}$ reported that aMED adherence was significantly associated with lower risk of cognitive impairment at $20 \mathrm{y} / \mathrm{u}$.

- McEvoy et $\mathrm{al}^{13}$ reported that higher vs. lower MedDiet adherence was significantly associated with less decline in cognitive function during $30 \mathrm{y} / \mathrm{u}$.

Studies reported no significant associations as follows:

- Haring et al ${ }^{11}$ reported that aMED score across quintiles was not significantly associated with mild cognitive impairment, probable dementia (PD), or incidence of either at $\sim 9 \mathrm{y} / \mathrm{u}$.

- Adjibade et al ${ }^{5}$ reported that MIND diet score was significantly associated with reduced risk of cognitive difficulty only in those age $\geq 70 \mathrm{y}$, and not significantly associated with cognitive difficulty in total sample at $6 y \mathrm{f} / \mathrm{u}$.

- Berendsen et $\mathrm{al}^{8}$ reported that long-term MIND score adherence was not significantly associated with change over time in the global cognitive or TICS scores over 6y f/u in women.

\section{DASH scores}

Studies reported lower risk of cognitive decline/impairment as follows:

- Wu et $\mathrm{al}^{25}$ reported that higher vs. lower DASH score was significantly associated with lower risk of cognitive impairment at $20 \mathrm{y} / \mathrm{u}$.

Studies reported no significant associations as follows: 
- Haring et al ${ }^{11}$ reported that DASH score across quintiles was not significantly associated with mild cognitive impairment, probable dementia, or incidence of either at $\sim 9 \mathrm{y} / \mathrm{u}$.

- Berendsen et $\mathrm{al}^{7}$ reported that highest DASH diet quintile vs. lowest was significantly associated with average cognitive function, but not significantly associated with change in cognitive function over $4 \mathrm{y} f / \mathrm{u}$ in women.

- McEvoy et al ${ }^{13}$ reported no significant association between DASH score and cognitive function.

- Shakersain et $\mathrm{al}^{19}$ reported that DASH adherence (continuous, or high vs. moderate) was not significantly associated with dementia over 6y f/u.

Country-specific indices/scores

Studies that reported lower risk of cognitive decline/impairment, as follows:

- Shakersain et al ${ }^{18,19}$ reported that higher vs. lower adherence (both continuously and categorically) to the Nordic Prudent dietary pattern in older adults was significantly associated with less MMSE decline at $6 y \mathrm{f} / \mathrm{u}$.

- Shakersain et al ${ }^{19}$ reported that BSD adherence, high vs. moderate, was not significantly associated with dementia over $6 y$ f/u. However, when BSD was examined continuously with cognitive decline as MMSE $\leq 24$, there was a significant association with lower risk of decline.

Studies that reported no significant associations, as follows:

- Voortman et $a^{23}$ reported that Dutch Dietary Guidelines adherence score was not significantly associated with dementia at median $13.5 \mathrm{y} / \mathrm{u}$.

- Mannikko et al ${ }^{12}$ reported that Nordic diet score was not significantly associated with cognitive function at $4 \mathrm{y} f / u$.

\section{Other indices/scores}

Studies that reported significantly lower risk of cognitive decline/impairment, i.e., better health outcomes, as follows:

- McEvoy et al ${ }^{13}$ reported that higher vs. lower APDQS adherence was significantly associated with less decline in cognitive function during $30 \mathrm{y} / \mathrm{u}$.

- Zhu et $a^{26}$ reported that higher vs. lower APDQS was significantly associated with better cognitive test results at $25 \mathrm{y} / \mathrm{u}$.

- Wu et $\mathrm{al}^{25}$ reported that higher vs. lower PDI or hPDI adherence scores were significantly associated with was significantly associated with lower risk of cognitive impairment at $20 \mathrm{y} f / \mathrm{u}$.

Studies that reported significantly higher risk of cognitive decline/impairment, as follows:

- Akbaraly et $\mathrm{al}^{6}$ reported that higher "Healthy food" scores at midline were significantly associated with greater cognitive decline during $25 \mathrm{y} / \mathrm{u}$.

Reduced Rank Regression (RRR)

Ozawa et al ${ }^{14}$ reported higher vs. lower "inflammatory" dietary pattern consumption was significantly associated with greater decline in cognitive function over $10 \mathrm{y} / \mathrm{u}$. 
Studies that reported lower risk of cognitive decline/impairment, as follows:

- Pearson et al ${ }^{15}$ examined five dietary patterns identified by factor analysis. Higher vs. lower consumption of the "alcohol/salads" dietary pattern, characterized by high loadings of green-leafy vegetables, tomatoes, salad dressing, wine and liquor, was significantly associated with lower odds of cognitive decline at $7 \mathrm{y} / \mathrm{f}$.

- Shakersain et al ${ }^{17}$ examined two dietary patterns identified by factor analysis: "Prudent" dietary pattern reflected more vegetables, fruit, cooking/dressing oil, cereals and legumes, whole grains, rice/pasta, fish, low-fat dairy, poultry, and water; whereas the "Western" dietary pattern reflected more red/processed meat, saturated/trans-fat, refined grains, sugar, beer, and spirits. Higher vs. lower adherence to the "Prudent" dietary pattern was significantly associated with less MMSE decline at 6y f/u. Highest adherence to the "Western" dietary pattern was significantly associated with more MMSE decline at 6y f/u, but this association was attenuated when accompanied by high "Prudent" dietary pattern adherence.

- Tomata et $\mathrm{al}^{22}$ reported higher adherence to the 'Japanese dietary pattern' (emphasizing fish, vegetables, mushrooms, potato, seaweeds, pickles, soybean, and fruits) was significantly associated with reduced dementia risk in older Japanese adults over a $6 \mathrm{y} / \mathrm{u}$. There was no significant association between the 'animal food' pattern or 'high-dairy' pattern and dementia risk.

Studies that reported no significant association, as follows:

- Dearborn-Tomazos et al ${ }^{10}$ examined two dietary patterns identified by factor analysis. Consumption of either the "Western" or "Prudent" dietary patterns ("Western": characterized by higher consumption of meats, refined grains, and fried foods; "Prudent": characterized by higher amounts of fruits and vegetables, fish, chicken, whole grains, dairy, nuts, and alcohol) at midlife was not significantly associated with global cognitive function, $20 \mathrm{y}$ change in cognitive function, or risk of dementia.

\section{Assessment of the evidence ${ }^{\text {ii }}$}

Of the 26 articles, four were included from RCTs and 22 articles from observational studies. There were few well-designed controlled trials upon which to draw stronger conclusions. However, findings from the observational studies were generally supportive of the findings from the RCTs. Overall, there was limited evidence that suggests that dietary patterns containing vegetables, fruits, unsaturated vegetable oils and/or nuts, legumes, and fish or seafood consumed during adulthood are associated with lower risk of age-related cognitive impairment and/or dementia. See the summary

\footnotetext{
ii A detailed description of the methodology used for grading the strength of the evidence is available on the NESR website: https://nesr.usda.gov/2020-dietary-guidelines-advisory-committee-systematicreviews and in Part C of the following reference: Dietary Guidelines Advisory Committee. 2020. Scientific Report of the 2020 Dietary Guidelines Advisory Committee: Advisory Report to the Secretary of Agriculture and the Secretary of Health and Human Services. U.S. Department of Agriculture, Agricultural Research Service, Washington, DC.
} 
of risk of bias for RCTs in Table 3 and observational studies in Table 4 for additional details. As outlined and described below, the body of evidence examining exposure and outcome was assessed for the following elements used when grading the strength of evidence

- Risk of bias: There were a number of potential risks of bias, or limitations, across the body of evidence (Table 3 and Table 4). While studies adjusted for most potential confounders, they did not adjust for all key confounders, including race/ethnicity and/or family history of neurocognitive disorders in particular. Several observational studies examined diet only once at baseline, and therefore, the effects of dietary patterns overtime may not be determined. However, several studies did examined diet at multiple time points over $\mathrm{f} / \mathrm{u}$, although there was a large range of time between assessments in some cases (e.g., a span of over 20 y). Several studies did not assess the impact of missing data, primarily due to criteria used when selecting subjects into the analyses. Many of the studies excluded participants with baseline dementia or conditions that may cause cognitive impairment, prevalent chronic diseases (e.g., cancer, CVD). Therefore, selected samples likely reflect generally healthier individuals. Some studies used telephone interviews to ascertain cognitive function outcomes of participants via self-reported data. Although the assessments were valid, these studies may be at higher risk of bias in outcome measurement.

- Consistency: Studies varied widely in the methods used to examine dietary patterns, including different indices/scores to examine adherence, factor/cluster analysis to identify dietary patterns, and reduced rank regression. Consistent direction and magnitude of effects were observed in 3 of the 4 RCTs, with generally supportive findings from many, but not all, observational studies. It is noteworthy that some studies showed either no significant associations or mixed associations when examining different dietary patterns among the same participants (i.e., within studies) or between studies. Despite variability in results, many of the studies supported dietary patterns associated with less cognitive decline or lower risk of dementia/cognitive impairment that share the following elements in common: vegetables, fruits, unsaturated vegetable oils and/or nuts, legumes, and fish or seafood. Less consistent elements that were considered across these "protective" dietary patterns included alcohol (wine preferred) and low-fat cheese and/or dairy products. Many of these dietary patterns also emphasized whole grains, non-refined grains, or (non-refined) breads/cereals. Fewer studies examined dietary patterns that relate to "worse" cognitive outcomes. Dietary patterns characterized as "unhealthy", emphasizing fried foods, processed and/or red meats, refined grains, desserts (pies, chocolate, sweets), and high-fat dairy products showed inconsistent findings, some associating with greater cognitive decline but primarily non-significant associations overall. Additionally, there was considerable variation in the outcome assessment methods used between studies, which included cognitive assessment techniques that may be insensitive. There was relative inconsistency in the magnitude and direction of findings within individual studies if multiple behavioral measures were used.

- Precision: All of the RCTs conducted power calculations and identified an adequate number of cases of possible and/or mild cognitive impairment or probable dementia with analytic sample sizes ranging from $n=137$ to $n=1606$ 
over an average f/u between $3 \mathrm{mo}$ and $8.5 \mathrm{y}$, with some degree of imprecision. Observational studies that reported significant results had relatively narrow confidence intervals, though results varied. Although these studies did not report sample size calculations, analytic sample sizes were generally large ranging from $n=1140$ to $n=27,860$.

- Directness: Most studies were designed to directly examine the relationship between the populations, intervention, comparators, and outcomes of interest related to the systematic review question. Several studies examined better/worse global cognition or performance on cognitive tests, which were less direct than the majority of studies examining incident cognitive impairment or dementia.

- Generalizability: The interventions and/or exposures, comparators, and outcomes examined in the body of evidence are likely applicable to the U.S. population. However, results are most generalizable to the generally healthy, older adults. Few studies reported information on or accounted for race/ethnicity of participants, and therefore, the results may be less generalizable in populations of diverse racial/ethnic backgrounds.

The 2020 Dietary Guidelines Advisory Committee updates, concurs, and builds upon the conclusion drawn by the 2015 Dietary Guidelines Advisory Committee. The 2015 Advisory Committee concluded that, limited evidence suggests that a dietary pattern containing an array of vegetables, fruits, nuts, legumes and seafood consumed during adulthood is associated with lower risk of age-related cognitive impairment, dementia and Alzheimer's disease. In 2015, although the number of studies available on dietary patterns and neurodegenerative disease risk is expanding, that body of evidence was made up of high-quality observational studies that appeared only in recent years, was rapidly developing, and employed a wide range of methodology in study design, definition and measurement ascertainment of cognitive outcomes and dietary pattern assessment. The newly published body of evidence has similar results with a similar volume of articles, though a few additional RCTs.

\section{Research recommendations}

In order to better assess the relationship between dietary patterns and neurocognitive health, future research may:

1. Examine the relationship between dietary patterns earlier in life and neurocognitive health to elucidate any preventative effects diet may have prior to the onset of cognitive impairment, after which diet may be less influential.

2. Explore objective measurements of brain function beyond the scope outlined for this review, such as structural magnetic resonance imaging scans with grey/white matter volume or density outputs (e.g., magnetization-prepared rapid acquisition with gradient echo (MPRAGE) data) and/or functional imaging techniques such as bloodoxygen level-dependent data (BOLD) (i.e., data from functional magnetic resonance imaging) or positron emission tomography (PET), which may provide additional insight into mechanisms that underlie cognitive impairment diagnoses and can potentially be connected to prevention strategies within the context of dietary patterns.

3. Utilize standardized behavioral assessments to determine cognitive decline.

4. Assess information regarding diet at more than one time-point, preferably during the 
course of follow-up, to facilitate determining change in dietary patterns over time.

5. Provide sufficient information and repeated measures on the quantification, i.e., types and amounts of foods/food groups comprising a dietary pattern, such as fruits and vegetables, and beverages such as alcohol, consumed.

6. Identify inadequate or excessive intakes of specific foods/food groups (e.g., fruits, vegetables, whole grains, legumes, EVOO, nuts, fish or seafood, and also, sugar sweetened beverages, processed foods including processed meats, added sugars, and salt) to better speak to diet quality due to the limited utility of the "total score" from a given dietary pattern (e.g., "Mediterranean diet", aHEI, and DASH scores).

7. Explore the relationship between dietary patterns and neurocognitive health further, particularly beyond the capacity of the current review by investigating factors such as

o weight status/BMI (e.g., to determine the response to dietary patterns in those who are classified as overweight or obese, or those with excess adiposity),

- physical activity (e.g., to determine the response to dietary patterns in those who may be sedentary compared to active),

- emerging biomarkers including metabolites and microbes reflecting different food-based patterns of intake and their associations with traditional chronic disease risk factors to more directly assess the relative preventative merits of various dietary patterns, and

- household food insecurity status (e.g., to determine the response to dietary patterns in those with higher or lower food security, with progressing or persistent household food insecurity, or food security insufficiency).

8. Include diverse populations with varying race/ethnicity, socioeconomic background, and chronic disease status, while ensuring to report the racial/ethnic background of participants studied.

9. Include conducting systematic reviews with a continuous model to better document the current state of science on high priority topics, such as the role of dietary patterns and neurocognitive health. 


\section{Included articles}

1. Chlebowski RT, Rapp S, Aragaki AK, et al. Low-fat dietary pattern and global cognitive function: exploratory analyses of the Women's Health Initiative (WHI) randomized Dietary Modification trial. EClinicalMedicine. 2020;18:100240. doi:10.1016/j.eclinm.2019.100240.

2. Marseglia A, Xu W, Fratiglioni L, et al. Effect of the NU-AGE diet on cognitive functioning in older adults: a randomized controlled trial. Front Physiol. 2018;9:349. doi:10.3389/fphys.2018.00349.

3. Knight A, Bryan J, Wilson C, Hodgson JM, Davis CR, Murphy KJ. The Mediterranean diet and cognitive function among healthy older adults in a 6-month randomised controlled trial: the MedLey Study. Nutrients. 2016;8(9). doi:10.3390/nu8090579.

4. Valls-Pedret C, Sala-Vila A, Serra-Mir M, et al. Mediterranean diet and age-related cognitive decline: a randomized clinical trial. JAMA Intern Med. 2015;175(7):1094-1103. doi:10.1001/jamainternmed.2015.1668.

5. Adjibade M, Assmann KE, Julia C, Galan P, Hercberg S, Kesse-Guyot E. Prospective association between adherence to the MIND diet and subjective memory complaints in the French NutriNet-Sante cohort. J Neurol. 2019;266(4):942-952. doi:10.1007/s00415-019-09218-y.

6. Akbaraly TN, Singh-Manoux A, Dugravot A, Brunner EJ, Kivimaki M, Sabia S. Association of midlife diet with subsequent risk for dementia. JAMA. 2019;321(10):957968. doi:10.1001/jama.2019.1432.

7. Berendsen AAM, Kang JH, van de Rest O, Feskens EJM, de Groot L, Grodstein F. The Dietary Approaches to Stop Hypertension diet, cognitive function, and cognitive decline in american older women. J Am Med Dir Assoc. 2017;18(5):427-432. doi:10.1016/j.jamda.2016.11.026.

8. Berendsen AM, Kang JH, Feskens EJM, de Groot C, Grodstein F, van de Rest O. Association of long-term adherence to the MIND diet with cognitive function and cognitive decline in american women. J Nutr Health Aging. 2018;22(2):222-229. doi:10.1007/s12603-017-0909-0.

9. Bhushan A, Fondell E, Ascherio A, Yuan C, Grodstein F, Willett W. Adherence to Mediterranean diet and subjective cognitive function in men. Eur J Epidemiol. 2018;33(2):223-234. doi:10.1007/s10654-017-0330-3.

10. Dearborn-Tomazos JL, Wu A, Steffen LM, et al. Association of dietary patterns in midlife and cognitive function in later life in us adults without dementia. JAMA Netw Open. 2019;2(12):e1916641. doi:10.1001/jamanetworkopen.2019.16641.

11. Haring B, Wu C, Mossavar-Rahmani $Y$, et al. No association between dietary patterns and risk for cognitive decline in older women with 9-year follow-up: data from the Women's Health Initiative Memory Study. J Acad Nutr Diet. 2016;116(6):921930.e921. doi:10.1016/j.jand.2015.12.017.

12. Mannikko R, Komulainen $P$, Schwab U, et al. The Nordic diet and cognition--The DR's EXTRA Study. Br J Nutr. 2015;114(2):231-239. doi:10.1017/s0007114515001890. 13. McEvoy CT, Hoang T, Sidney S, et al. Dietary patterns during adulthood and cognitive performance in midlife: the CARDIA study. Neurology. 2019;92(14):e1589e1599. doi:10.1212/wnl.0000000000007243. 
14. Ozawa M, Shipley M, Kivimaki M, Singh-Manoux A, Brunner EJ. Dietary pattern, inflammation and cognitive decline: the Whitehall II prospective cohort study. Clin Nutr. 2017;36(2):506-512. doi:10.1016/j.clnu.2016.01.013.

15. Pearson KE, Wadley VG, McClure LA, Shikany JM, Unverzagt FW, Judd SE.

Dietary patterns are associated with cognitive function in the REasons for Geographic And Racial Differences in Stroke (REGARDS) cohort. J Nutr Sci. 2016;5:e38.

doi:10.1017/jns.2016.27.

16. Richard EL, Laughlin GA, Kritz-Silverstein D, Reas ET, Barrett-Connor E, McEvoy LK. Dietary patterns and cognitive function among older community-dwelling adults. Nutrients. 2018;10(8). doi:10.3390/nu10081088.

17. Shakersain B, Santoni G, Larsson SC, et al. Prudent diet may attenuate the adverse effects of Western diet on cognitive decline. Alzheimers Dement. 2016;12(2):100-109. doi:10.1016/j.jalz.2015.08.002.

18. Shakersain $B$, Rizzuto $D$, Wang $H X$, et al. An active lifestyle reinforces the effect of a healthy diet on cognitive function: a population-based longitudinal study. Nutrients. 2018;10(9). doi:10.3390/nu10091297.

19. Shakersain B, Rizzuto D, Larsson SC, Faxen-Irving G, Fratiglioni L, Xu WL. The Nordic Prudent diet reduces risk of cognitive decline in the Swedish older adults: a population-based cohort study. Nutrients. 2018;10(2). doi:10.3390/nu10020229.

20. Shannon OM, Stephan BCM, Granic A, et al. Mediterranean diet adherence and cognitive function in older UK adults: the European Prospective Investigation into Cancer and Nutrition-Norfolk (EPIC-Norfolk) Study. Am J Clin Nutr. 2019;110(4):938948. doi:10.1093/ajen/nqz114.

21. Smyth $A$, Dehghan M, O'Donnell M, et al. Healthy eating and reduced risk of cognitive decline: a cohort from 40 countries. Neurology. 2015;84(22):2258-2265. doi:10.1212/wnl.0000000000001638.

22. Tomata $\mathrm{Y}$, Sugiyama K, Kaiho $\mathrm{Y}$, et al. Dietary patterns and incident dementia in elderly Japanese: the Ohsaki Cohort 2006 study. J Gerontol A Biol Sci Med Sci. 2016;71(10):1322-1328. doi:10.1093/gerona/glw117.

23. Voortman T, Kiefte-de Jong JC, Ikram MA, et al. Adherence to the 2015 Dutch dietary guidelines and risk of non-communicable diseases and mortality in the Rotterdam Study. Eur J Epidemiol. 2017;32(11):993-1005. doi:10.1007/s10654-0170295-2.

24. Wagner M, Grodstein F, Proust-Lima C, Samieri C. Long-term trajectories of body weight, diet, and physical activity from midlife through late-life and subsequent cognitive decline in women. Am J Epidemiol. 2019. doi:10.1093/aje/kwz262.

25. Wu J, Song X, Chen GC, et al. Dietary pattern in midlife and cognitive impairment in late life: a prospective study in Chinese adults. Am J Clin Nutr. 2019;110(4):912-920. doi:10.1093/ajcn/nqz150.

26. Zhu N, Jacobs DR, Meyer KA, et al. Cognitive function in a middle aged cohort is related to higher quality dietary pattern 5 and 25 years earlier: the CARDIA study. $J$ Nutr Health Aging. 2015;19(1):33-38. doi:10.1007/s12603-014-0491-7. 27. Dietary Guidelines Advisory Committee. Scientific Report of the 2015 Dietary Guidelines Advisory Committee: Advisory Report to the Secretary of Health and Human Services and the Secretary of Agriculture. Washington, DC: US Department of Agriculture, Agricultural Research Service. https://health.gov/sites/default/files/201909/Scientific-Report-of-the-2015-Dietary-Guidelines-Advisory-Committee.pdf. Published 2015. Accessed June 25, 2020. 
Table 1: Description of randomized controlled trials that examined the relationship between dietary patterns and cognitive impairment, dementia, or Alzheimer's disease ${ }^{\mathrm{iii}}$

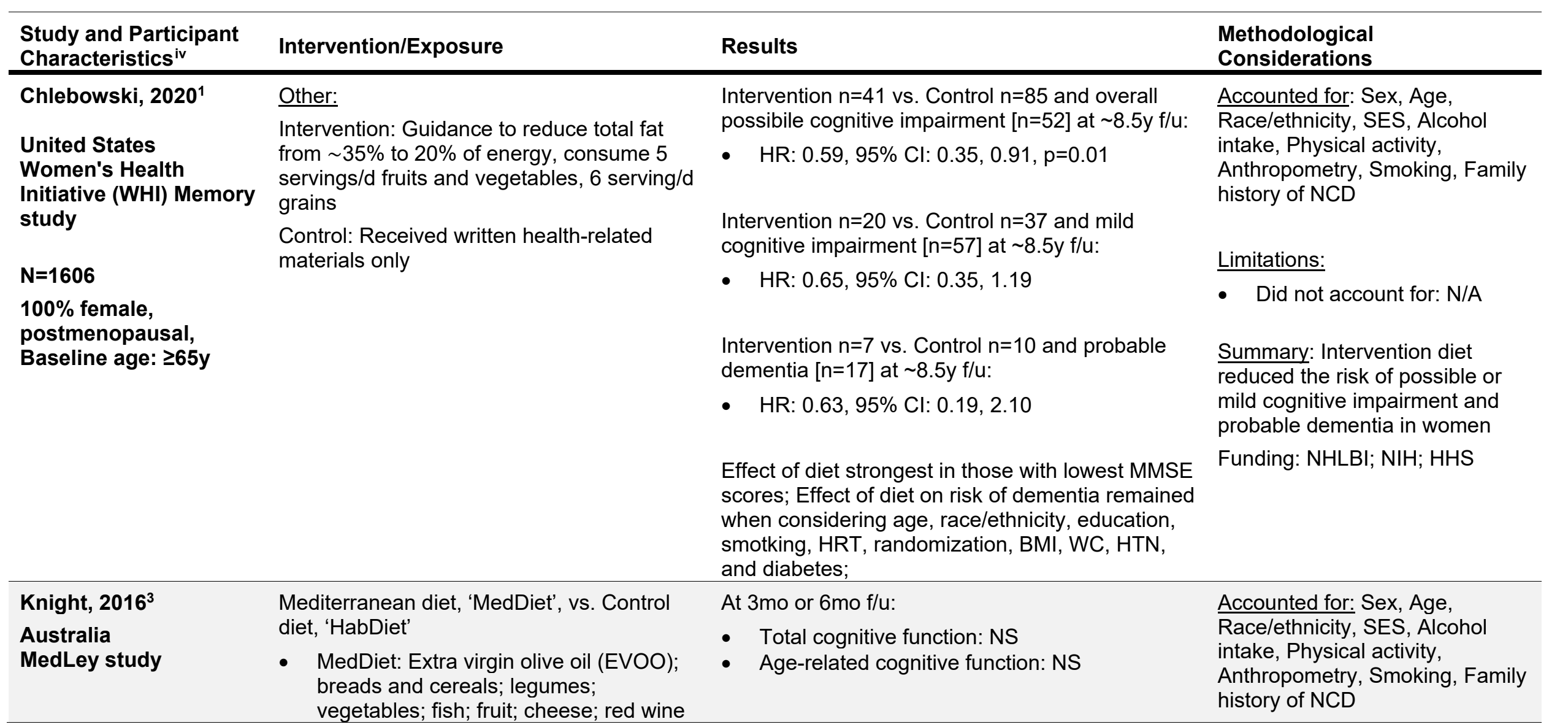

\footnotetext{
iii Abbreviations: CERAD, Consortium to Establish a Registry for Alzheimer's Disease Battery; EVOO, extra-virgin olive oil; GMS, Geriatric Mental Schedule; HHS, U.S. Department of Health and Human Services; ITT, intent-to-treat analyses; N/A, Not applicable; NCD, Neurocognitive disorder; NHLBI, National Heart Lung and Blood Institute; NIH, National Institutes of Health; NS, Not significant; NR, Not reported; MMSE, Mini-Mental State Examination ; Mo, month or months; SF-EMSE, Short Form Extended Mental State Exam; SMC, Subjective memory complaints; TICS, Telephone Interview for Cognitive Status - telephone adaption of MMSE to assess overall cognitive performance; wk, week(s); y, year(s)

iv Includes last name of first author, publication year, country, name of the cohort or study if reported, analytic sample size, and select participant characteristics of the analytic sample
} 


\begin{tabular}{|c|c|c|c|}
\hline $\begin{array}{l}\text { Study and Participant } \\
\text { Characteristicsiv }\end{array}$ & Intervention/Exposure & Results & $\begin{array}{l}\text { Methodological } \\
\text { Considerations }\end{array}$ \\
\hline $\begin{array}{l}\mathrm{N}=137 \\
\text { Baseline age: } \sim 72 \mathrm{y} \\
\text { Exclusions: conditions } \\
\text { that may cause } \\
\text { cognitive impairment }\end{array}$ & $\begin{array}{l}\text { (upon participants choice, not } \\
\text { compulsory); Greek yoghurt; nuts; } \\
\text { potato (white); milk; eggs provided; } \\
\text { "Free foods": legumes, Greek yoghurt, } \\
\text { Australian EVOO, canned tuna, walnuts, } \\
\text { peanuts and almonds } \\
\text { - Control: consume customary dietary } \\
\text { pattern with supermarket gift vouchers }\end{array}$ & & $\begin{array}{l}\text { Limitations: } \\
\text { - Did not account for: N/A } \\
\text { Summary: MedDiet consumption } \\
\text { did not improve or worsen } \\
\text { cognitive function after } 3 \text { or } 6 \text { mo } \\
\text { Funding: National Health } \\
\text { Medical Research Council } \\
\text { (NHMRC); University of South } \\
\text { Australia Postgraduate Award }\end{array}$ \\
\hline $\begin{array}{l}\text { Marseglia, } 2018^{2} \\
\text { France, Italy, } \\
\text { Netherlands, Poland, } \\
\text { United Kingdom } \\
\text { NU-AGE } \\
\text { N=1144 } \\
\text { Baseline age: } 65-79 y \\
\text { Exclusions: heart } \\
\text { diseases, diabetes, } \\
\text { chronic corticosteroid } \\
\text { user, recent antibiotic } \\
\text { user, recent change in } \\
\text { habitual medication } \\
\text { use, frailty, } \\
\text { malnutrition, or those } \\
\text { on special diets. }\end{array}$ & $\begin{array}{l}\text { Other: } \\
\text { "Nu-AGE" diet (provided participants with } \\
\text { whole grain pasta, margarine rich in PUFA } \\
\text { and MUFA, low fat, low-salt cheese, extra } \\
\text { virgin olive oil (EVOO) and frozen vegetable } \\
\text { soup) adherence vs. habitual diet control } \\
\text { group; analyzed in tertiles (low, moderate, } \\
\text { high) }\end{array}$ & 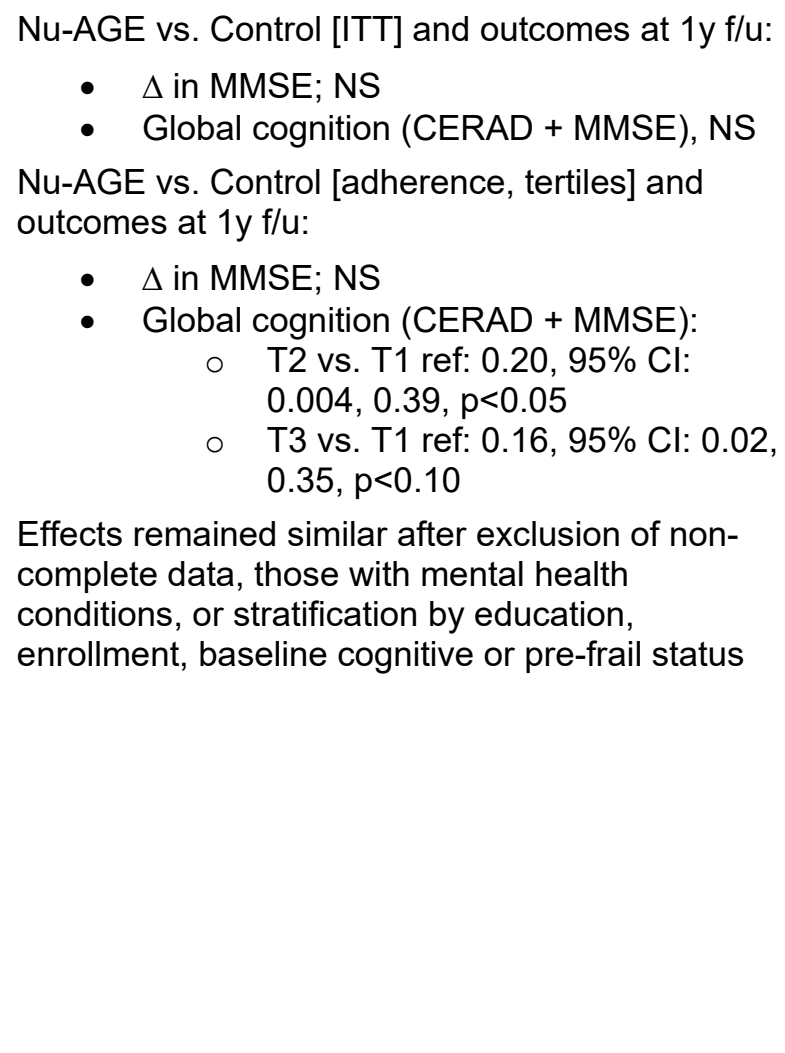 & $\begin{array}{l}\text { Accounted for: Sex, Age, SES: } \\
\text { Education, Anthropometry, } \\
\text { Other: Enrollment country, } \\
\text { Interviewer, Pre-frailty } \\
\text { Limitations: } \\
\text { - Did not account for: } \\
\quad \text { Race/ethnicity, Alcohol } \\
\text { intake, Physical activity, } \\
\text { Smoking, Family history of } \\
\quad \text { NCD [data not shown } \\
\quad \text { regarding these factors] } \\
\\
\text { Summary: Participants with } \\
\text { higher vs. lower Nu-AGE diet } \\
\text { adherence had significant } \\
\text { improvements in global cognition } \\
\text { and episodic memory scores. No } \\
\text { significant differences between } \\
\text { groups in global cognition or } \\
\text { cognitive domains after 1y. } \\
\text { Funding: European Union's } \\
\text { Seventh Framework Program; } \\
\text { Swedish Research Council; the }\end{array}$ \\
\hline
\end{tabular}




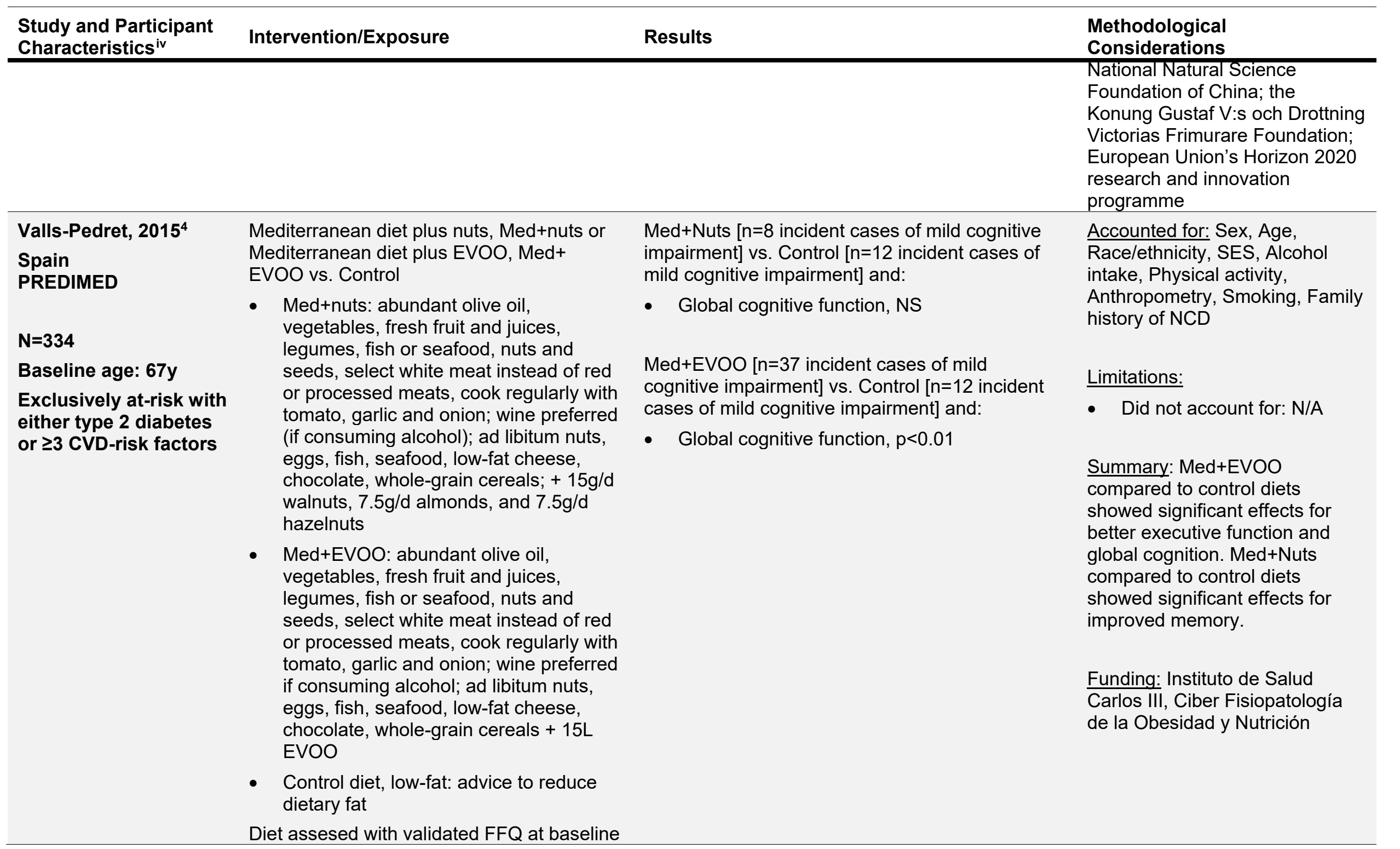




\title{
Table 2: Description of observational studies that examined the relationship between dietary patterns and cognitive
} impairment, dementia, or Alzheimer's disease ${ }^{v}$

\begin{tabular}{|c|c|c|c|}
\hline $\begin{array}{l}\text { Study and } \\
\text { Participant } \\
\text { Characteristics }\end{array}$ & Intervention/Exposure & Results & Methodological Considerations \\
\hline $\begin{array}{l}\text { Adjibade, } 2019^{5} \\
\text { France } \\
\text { Prospective } \\
\text { cohort study } \\
\text { NutriNet-Sante } \\
\text { cohort } \\
\text { N=6011 } \\
\text { Baseline age: } \\
\geq 60 y\end{array}$ & $\begin{array}{l}\text { Index analysis: } \\
\text { Mediterranean-DASH diet intervention for } \\
\text { neurodegenerative delay (MIND) diet } \\
\text { adherence score by tertiles and } \\
\text { continuous } \\
\text { - "Healthy brain foods": green leafy } \\
\text { vegetables, other vegetables, nuts, } \\
\text { berries, beans, whole grains, fish, } \\
\text { poultry, olive oil, and wine } \\
\text { - "Unhealthy brain foods": red meats, } \\
\text { butter and margarine, cheese, } \\
\text { pastries and sweets, and fast fried } \\
\text { Sensitivity analyses conducted with the } \\
\text { dietary-only French Programme National } \\
\text { Nutrition Santé-Guideline Score (mPNNS- } \\
\text { GS) } \\
\text { Diet collected every 2y with validated 24-h } \\
\text { dietary records }\end{array}$ & $\begin{array}{l}\text { MIND score and risk of high cognitive difficulties } \\
\text { (Subjective memory complaints, } S M C \geq 43 \text { ) at } 6 y \\
\text { f/u: NS } \\
\text { MIND score in age } \geq 60 y \text { and risk of high } \\
\text { cognitive difficulties at } 6 y \text { f } / \mathrm{u} \text { : NS } \\
\text { MIND score in age } 70+y \text { and risk of high } \\
\text { cognitive difficulties at } 6 y \text { f/u: } \\
\text { - Continuous: HR: } 0.87,95 \% \mathrm{Cl}: 0.78 \text {; } \\
\quad 0.98 ; p=0.02 \\
\text { - T3 vs. T1 ref: NS } \\
\text { - T2 vs. T1 ref: NS } \\
\text { mPNNS-GS and risk of high cognitive difficulties } \\
\text { at } 6 y \text { f/u: NS }\end{array}$ & $\begin{array}{l}\text { Accounted for: Sex, Age, SES: Marital } \\
\text { status, Education, Occupation, Income, } \\
\text { Anthropometry: BMI, Alcohol: Part of } \\
\text { dietary pattern, Physical activity, } \\
\text { Smoking; Other: energy intake, number of } \\
\text { recording days, inclusion month, } \\
\text { comborbid conditions, depressive } \\
\text { symptoms, baseline SMC } \\
\text { Limitations: } \\
\text { Did not account for: Race/ethnicity, } \\
\quad \text { Family history of NCD } \\
\text { Summary: MIND diet score was } \\
\text { significantly associated with reduced risk } \\
\text { of cognitive difficulty only in those age } \\
\geq 70 y, \text { and not significantly associated with } \\
\text { cognitive difficulty in total sample at 6y f/u. } \\
\text { Funding: French Ministry of Health; } \\
\text { French Public Health Agency; French } \\
\text { National Institute for Health and Medical } \\
\text { Research; Medical Research Foundation; }\end{array}$ \\
\hline
\end{tabular}

\begin{abstract}
${ }^{v}$ Abbreviations: CERAD, Consortium to Establish a Registry for Alzheimer's Disease Battery; EVOO, extra-virgin olive oil; GMS, Geriatric Mental Schedule; HHS, Department of Health and Human Services; MIND, Mediterranean-DASH diet intervention for neurodegenerative delay; MMSE, Mini-Mental State Examination; mo, month(s); N/A, Not applicable; NCD, Neurocognitive disorder; NIA, National Institute on Aging; NHLBI, National Heart Lung and Blood Institute; NIH, National Institutes of Health; NS, Not significant; NR, Not reported; RAVLT, Rey's Auditory Verbal Learning Test; SES, Socioeconomic status; SF-EMSE, Short Form Extended Mental State Exam; SMC, Subjective memory complaints; TICS, Telephone Interview for Cognitive Status - telephone adaption of MMSE to assess overall cognitive performance; wk, week(s); y, year(s)

vi Includes last name of first author, publication year, country, name of the cohort or study if reported, analytic sample size, and select participant characteristics of the analytic sample
\end{abstract}




\section{Study and}

Participant

Characteristics $^{\text {vi }}$

\section{Methodological Considerations}

French National Institute for Agricultural

Research; National Conservatory for Arts and Crafts; National Institute for

Prevention and Health Education; Paris 13 University

\section{Akbaraly, $2019^{6}$ \\ United Kingdom \\ Prospective \\ cohort study}

\section{$\mathrm{N}=8225$}

Baseline age: $\sim 50 \mathrm{y}$

\section{Index analysis:}

Adherence to the Alternate Healthy Eating Index (AHEI)-2010 score, categorical tertiles and continuous per-1-SD increase

- Positive: vegetables, fruits, whole grains, nuts and legumes, n-3 fatty acids, and PUFAs;

- Negative: SSB and fruit juice, red and processed meat, trans fat, $\mathrm{Na}+$;

- Moderate: Alcohol

\section{Factor analysis}

Adherence scores for two dietary patterns identified by factor analysis, categorical tertiles and continuous per-1-SD increase at 1991-1993; 1997-1999; and 20022004:

- "Healthy food": high intake of vegetables, fruits, and fish

- "Western-type": high consumption of fried food, processed and red meat, pies, chocolate, sweets, high-fat dairy products, and refined grains

Diet assesed at multiple time points at 1991-1993; 1997-1999; and 2002-2004

\section{aHEI-2010 and outcomes during $25 \mathrm{y} f / \mathrm{u}$}

- aHEI-2010 at 1991-1993, per-1-SD or tertiles

- Dementia, NS

- Global cogntive-z,NS

- 18-y Cognitive decline, NS

- aHEI-2010 at 1997-1999, per-1-SD or tertiles

- Dementia, NS

- aHEI-2010 at 2002-2004, per-1-SD or tertiles

\section{- Dementia, NS}

"Healthy food" and outcomes during 25y f/u

- "Healthy food", per-1-SD or tertiles - Dementia, NS

- Global cogntive-z, NS

- 18-y Cognitive decline,

- Per-1-SD: HR: -0.03, $95 \% \mathrm{Cl}:-0.05,-0.01$, $\mathrm{p}=0.007$

- T3 vs. T1 ref: HR: $0.06,95 \% \mathrm{Cl}:-0.11$, 0.01

- T2 vs. T1 ref: NS

- "Healthy food" at 1997-1999, per-1-SD or tertiles

- Dementia, NS

- "Healthy food" at 2002-2004, per-1-SD or tertiles
Accounted for: Sex, Age, Race/ethnicity, SES, Anthropometry, Alcohol intake, Physical activity, Smoking, Other: chronic diseases, depressive symptoms, CVDmedication, dementia status over $\mathrm{f} / \mathrm{u}$

\section{Limitations:}

- Did not account for: Family history of NCD

Summary: AHEl-2010 scores during midlife was not significantly associated with subsequent risk for dementia or cognitive decline; higher "Healthy food" scores at midline were significantly associated with greater cognitive decline during $25 \mathrm{y} f / \mathrm{u}$

Funding: UK Medical Research Council; British Heart Foundation; British Health and Safety Executive; NHLBI; NIA; Economic and Social Research Council 
"Western-type" and outcomes during 25y f/u

- "Western-type" at 1991-1993, per-1-SD or tertiles

- Dementia, NS

- Global cogntive-z, NS

18-y Cognitive decline, NS

- "Western-type" at 1997-1999

- Dementia, NS

- "Western-type" at 2002-2004

\section{Berendsen, 2018 ${ }^{8}$ Index analysis:}

United States

Prospective

cohort study

Nurses' Health

Study (NHS)

$\mathrm{N}=16058$

$100 \%$ female,

Baseline age:

$\geq 70 y$ food
MIND diet adherence by quintile

- "Healthy brain foods": green leafy vegetables, other vegetables, nuts, berries, beans, whole grains, fish, poultry, olive oil, and wine

- "Unhealthy brain foods": red meats, butter and margarine, cheese, pastries and sweets, and fried/fast

Diet assesed five times between 19841998, MIND score based on mean over 5 assessments
MIND diet across quintiles and mean difference in cognition over 6y:

- Global cognition, NS

- Cognitive performance (TICS), NS

MIND diet across quintiles and cognitive change over 6y:

- Global cognition, NS

- $\quad$ Cognitive performance (TICS), NS
Accounted for: Sex, Age, SES: Education, Anthropometry, Alcohol intake, Physical activity, Smoking, Other: total energy intake, history of depression, multivitamin use, CVD factors

\section{Limitations:}

- Did not account for Race/ethnicity, Family history of NCD

Summary: Long-term MIND score adherence was not significantly associated with change over time in the global cognitive or TICS scores over $6 y$ $\mathrm{f} / \mathrm{u}$ in women

Funding: NIH; National Cancer Institute; National Institute of Diabetes and Digestive and Kidney Diseases; NIA;

NHLB 


\begin{tabular}{|c|c|}
\hline $\begin{array}{l}\text { Study and } \\
\text { Participant } \\
\text { Characteristics }^{\mathrm{vi}}\end{array}$ & Intervention/Exposure \\
\hline Berendsen, $2017^{7}$ & Index analysis: \\
\hline $\begin{array}{l}\text { United States } \\
\text { Prospective }\end{array}$ & $\begin{array}{l}\text { Dietary Approaches to Stop Hypertension } \\
\text { (DASH) diet adherence score }\end{array}$ \\
\hline $\begin{array}{l}\text { cohort study } \\
\text { Nurses' Health } \\
\text { Study (NHS) }\end{array}$ & $\begin{array}{l}\text { DASH score: based on high intake of } \\
\text { fruits, vegetables, nuts and legumes, } \\
\text { whole grains, low-fat dairy products, } \\
\text { and low intake of sodium, red and }\end{array}$ \\
\hline$N=16144$ & $\begin{array}{l}\text { processed meats, and sweetened } \\
\text { beverages: MUFA+PUFA }\end{array}$ \\
\hline $\begin{array}{l}100 \% \text { fem } \\
\text { Baseline }\end{array}$ & $\begin{array}{l}\text { Diet assesed five times between 1984- } \\
1998\end{array}$ \\
\hline
\end{tabular}
1998

\section{United States}

Prospective

cohort study

Health

Professionals'

Follow-up Study

(HPFS)

$\mathrm{N}=\mathbf{2 7 8 4 2}$

$0 \%$ female,

Baseline age: 40-

75y

\section{Index analysis:}

Adherence to the Mediterranean diet score (MDS):

- Positive components: vegetables, legumes, fruits and nuts, cereals, MUFA: SFA ratio, and fish

- Negative components: red meat, poultry, and dairy products

- Moderate: alcohol

Diet assesed five times between 19862002, MDS based on mean over 5 assessments

\section{Results}

DASH diet across quintiles and average

cognitive function over $4 \mathrm{y}$ :

Global cognition

- Q3, Q2 vs. Q1 ref, NS

- Q4 vs. Q1 ref: $0.04,95 \% \mathrm{Cl}: 0.01,0.07$

- Q5 vs. Q1 ref: $0.03,95 \%$ Cl: $0.00,0.06$

- P-trend=0.009

Cognitive performance (TICS)

- Q2, Q3, Q4 vs. Q1 ref, NS

- Q5 vs. Q1 ref: $0.16,95 \% \mathrm{Cl}: 0.03,0.29$

- P-trend $=0.002$

- No interaction for age, high blood pressure, or ApoE e4 status; no mediation by blood pressure

DASH diet across quintiles and cognitive change over 4y:

- Global cognition, NS

- Cognitive performance (TICS), NS

Highest vs. lowest mean MDS and outcomes at f/u:

Moderate cognitive function (SCF 1-2)

\section{Methodological Considerations}

Accounted for: Sex, Age, SES: Education, Anthropometry, Alcohol intake, Physical activity, Smoking, Other: total energy intake, history of depression, multivitamin use, CVD factors

\section{Limitations:}

- Did not account for Race/ethnicity, Family history of NCD

Summary: Highest DASH diet quintile vs. lowest was significantly associated with average cognitive function, but not significantly associated with cognitive change over $4 \mathrm{y} f / \mathrm{u}$ in women.

Funding: NIH; National Cancer Institute; National Institute of Diabetes and Digestive and Kidney Diseases; NIA; NHLBI

Accounted for: Sex, Age, Anthropometry, Alcohol intake: Part of dietary pattern Physical activity, Smoking, Other: diabetes, hypertension, depression, hypercholesterolemia

Q2 or Q3 vs. Q1 ref, NS

- Q4 vs. Q1 ref: OR: $0.84,95 \%$ Cl: 0.77 , 0.91

- Q5 vs. Q1 ref: OR: 0.76, $95 \%$ Cl: 0.70 , 0.83

- P-trend $<0.001$

Poor cognitive function (SCF $\geq 3$ )

- Q2 vs. Q1 ref, NS

- Q3 vs. Q1 ref: OR: 0.74, $95 \%$ Cl: 0.64 , 0.86

\section{Limitations:} SES, Physical activity,

Anthropometry, Family history of NCD

Summary: Higher vs. lower

Mediterranean dietary pattern adherence
- Did not account for: Race/ethnicity, 


\section{Study and}

Participant

Characteristics $^{\text {vi }}$

\section{Results}

Q4 vs. Q1 ref: OR: 0.67, $95 \%$ Cl: 0.57, 0.78

- Q5 vs. Q1 ref: OR: 0.64, $95 \%$ Cl: 0.55, 0.75

- $\quad$ P-trend $<0.001$

\section{Methodological Considerations}

is significantly associated prospectively with better cognitive function in men Funding: Harvard T H Chan School of Public Health; NIH

\section{Dearborn- \\ Tomazos, 201910 \\ United States \\ Prospective cohort study \\ Atherosclerosis \\ Risk in \\ Communities \\ (ARIC) \\ $\mathrm{N}=13588$ \\ Baseline age: \\ $\sim 55 y$ \\ Excluded those \\ who were neither \\ white nor black}

\section{Factor analysis:}

Two dietary patterns identifed:
- "Western": characterized by higher consumption of meats, refined grains, and fried foods.

- "Prudent": characterized by higher amounts of fruits and vegetables, fish chicken, whole grains, dairy, nuts, and alcohol

Diet assesed once at baseline with FFQ
"Western" dietary pattern tertiles and outcomes:

- visit 2 cogntive function, NS

- $20 y \Delta$ in global cognitive function, NS

- Dementia risk, NS

"Prudent" dietary pattern tertiles and outcomes:

- visit 2 cogntive function, NS

- $20 y \Delta$ in global cognitive function, NS

- Dementia risk, NS

Accounted for: Sex, Age, Race/ethnicity, SES: Education, Anthropometry, Alcohol intake: Part of dietary pattern, Physical activity, Smoking, Other: race-field center, total energy intake, total cholesterol,

$\mathrm{CHD}$, history of hypertension, diabetes, stroke, ApoE4 status

\section{Limitations:}

- Did not account for Race/ethnicity, Family history of NCD

- Diet assessed only once at baseline

Summary: "Western" or "Prudent" dietary patterns at midlife was not significantly associated with global cognitive function, $20 y$ change in cognitive function, or risk of dementia

Funding: NHLBI, NIH, DHHS

Haring, 2016
United States
Prospective
cohort study
Women's Health
Initiative (WHI)
Memory study

\section{Index analysis:}

Adherence scores for multiple dietary patterns:

- alternate Mediterranean diet score aMED, (Fung, 2005): positively scored vegetables (not potatoes), fruit, legumes, nuts, whole grains, fish, MUFA/SFA, and moderate
aMED and risk over $\sim 9 \mathrm{y} / \mathrm{u}$ :

- Mild Cognitive Impairment (MCI), NS

- Probable Dementia (PD), NS

- Q3 vs. Q1 ref: HR: $1.47,95 \%$

$$
\text { Cl: } 1.05,2.06
$$

- $\mathrm{MCl}$ or PD, NS

HEl-2010 and risk over $\sim 9 y$ f/u:

\section{Accounted for:}

Sex, Age, Race/ethnicity, SES:

Education, Income, Anthropometry, Alcohol: Part of dietary pattern, Physical activity, Smoking, Other: Hormone trial arm, baseline 3MSE, diabetes,

hypertension status, depression, history of CVD, total energy intake 


\begin{tabular}{|c|c|c|c|}
\hline $\begin{array}{l}\text { Study and } \\
\text { Participant } \\
\text { Characteristics }^{\mathrm{vi}}\end{array}$ & Intervention/Exposure & Results & Methodological Considerations \\
\hline \multirow[t]{2}{*}{$\begin{array}{l}\mathrm{N}=6425 \\
100 \% \text { female, } \\
\text { Baseline age: } 65- \\
79 y \\
\text { Exclusively } \\
\text { postmenopausal }\end{array}$} & $\begin{array}{l}\text { alcohol; negatively scored red and } \\
\text { processed meat } \\
\text { Healthy Eating Index-2010, HEI-2010 } \\
\text { (Guenther, 2013): positively scored } \\
\text { total vegetables and greens and } \\
\text { beans, total and whole fruit, whole } \\
\text { grains, fatty acids, seafood and plant } \\
\text { proteins, and dairy; negatively scored } \\
\text { refined grains, added sugars, solid } \\
\text { fats, and excess alcohol (13g/1000 } \\
\text { kcal) in "empty calories", and sodium } \\
\text { alternate Healthy Eating Index 2010, } \\
\text { AHEl-2010 (Chiuve, 2012): positively } \\
\text { scored vegetables (not potatoes, } \\
\text { French fries), fruit, legumes and nuts, } \\
\text { whole grains, long-chain fats and } \\
\text { PUFA, moderate alcohol, and } \\
\text { adjusted emphasis on plant proteins; } \\
\text { negatively scored red and processed } \\
\text { meat, sugar-sweetened beverages } \\
\text { and fruit juice, trans fat, and sodium } \\
\text { Dietary Approach to Stop } \\
\text { Hypertension (DASH) score (Fung, } \\
\text { 2008): positively scored vegetables } \\
\text { (not potatoes), fruit and fruit juice, } \\
\text { legumes and nuts, whole grains, and } \\
\text { low-fat dairy; negatively scored red } \\
\text { and processed meat, sugar- } \\
\text { sweetened beverages, and sodium }\end{array}$ & 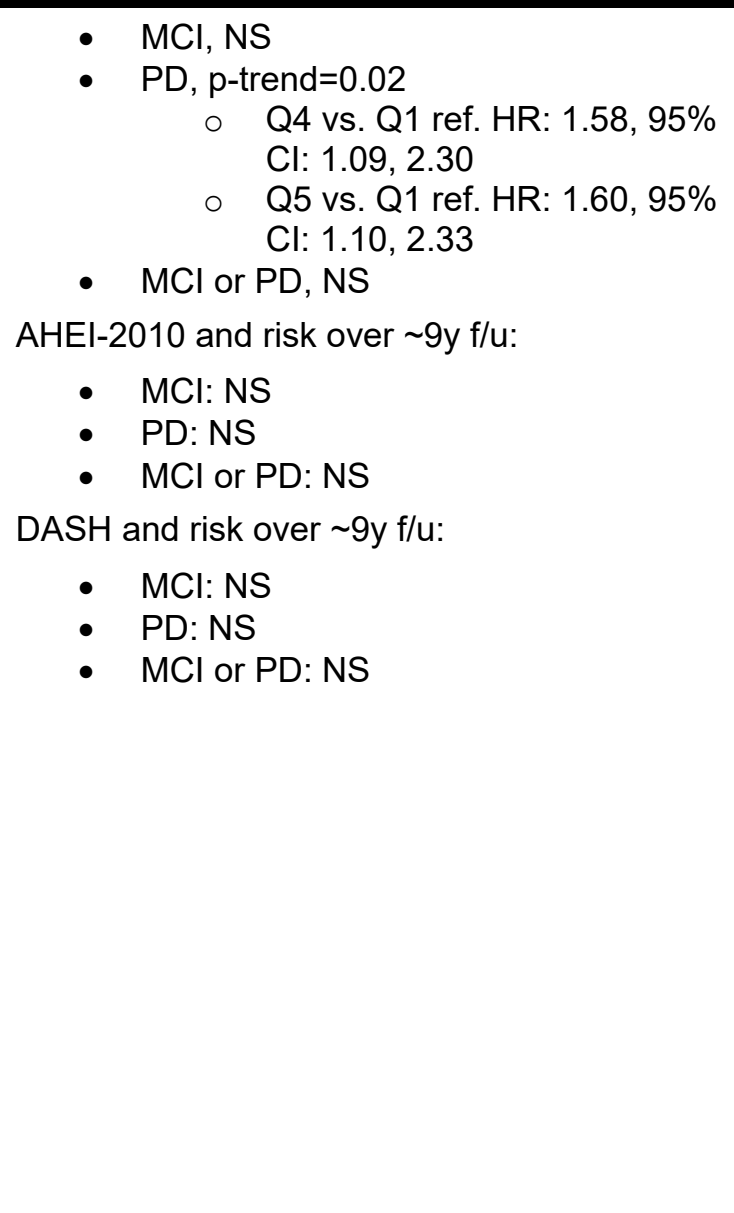 & $\begin{array}{l}\text { Limitations: } \\
\text { - Did not account for Family history of } \\
\text { NCD } \\
\text { - Diet assessed only once at baseline } \\
\text { Summary: aMED, HEI-2010, AHEI-2010, } \\
\text { or DASH scores across quintiles were not } \\
\text { significantly associated with mild } \\
\text { Cognitive Impairment, Probable Dementia } \\
\text { (PD), or incidence of either at } \sim 9 y \mathrm{f} / \mathrm{u} \\
\text { Funding: NHLBI, NIH, DHHS }\end{array}$ \\
\hline & $\begin{array}{l}\text { Diet assesed once at baseline with } \\
\text { validated FFQ }\end{array}$ & & \\
\hline $\begin{array}{l}\text { Mannikko, } 2015^{12} \\
\text { Finland }\end{array}$ & $\begin{array}{l}\text { Index analysis: } \\
\text { Adherence for the Nordic Diet Score } \\
\text { (modified Kanerva, 2014) }\end{array}$ & $\begin{array}{l}\text { In the total cohort, } n=1140 \text {, and those with } \\
\text { normal cognition at baseline, } n=1042 \text { : } \\
\text { - Global cognition (CERAD) at } 4 y \text { f/u: NS }\end{array}$ & $\begin{array}{l}\text { Accounted for: } \\
\text { Sex, Age, , SES: education, Smoking, } \\
\text { Other: } \mathrm{VO}_{2 \max }, \text { antihypertensive }\end{array}$ \\
\hline
\end{tabular}




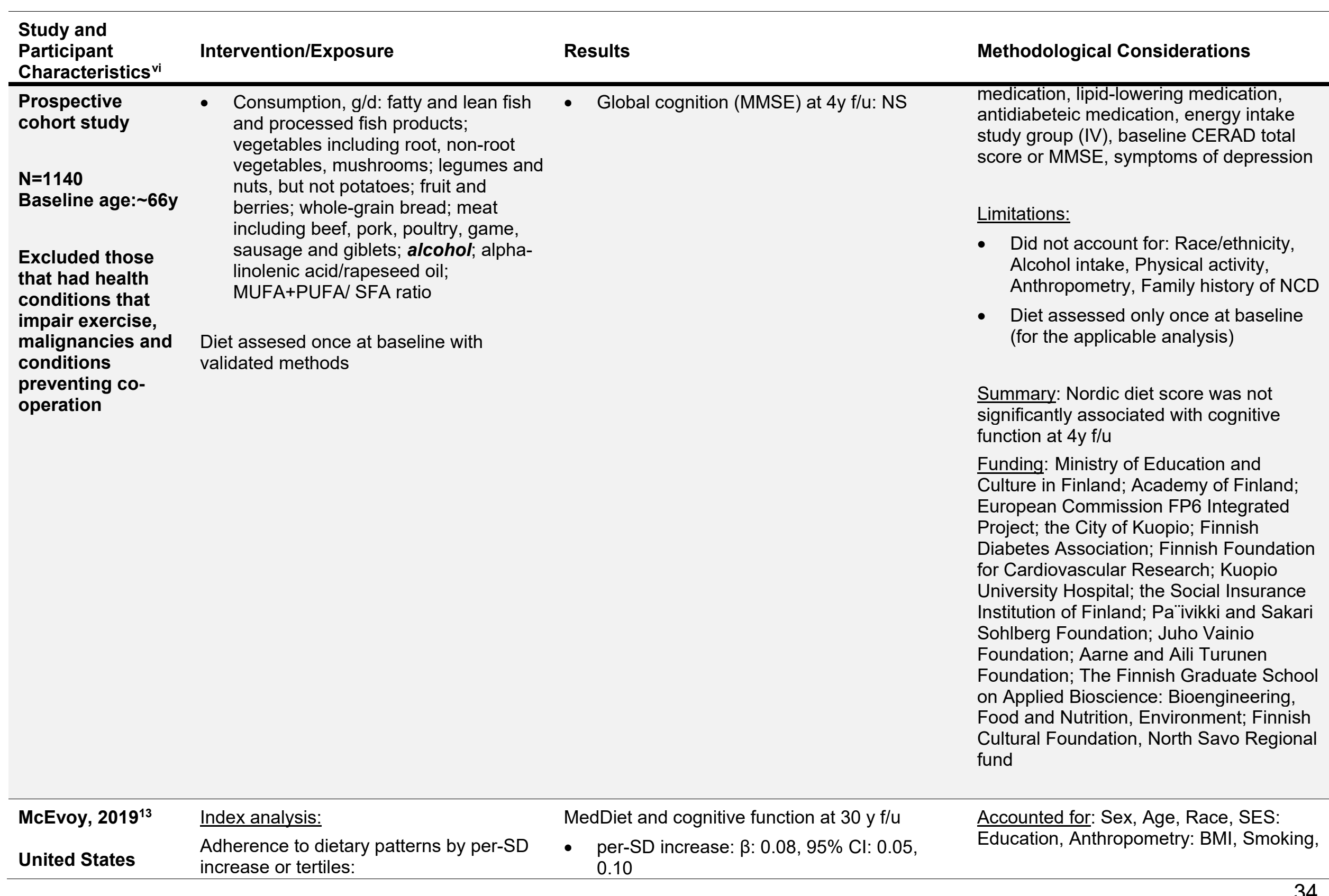


Study and

Participant Characteristics $^{\text {vi }}$

Coronary Artery

Risk Development

in Young Adults

(CARDIA)

Prospective

cohort study

$\mathrm{N}=2621$

Baseline age: $25 y$

\section{Excluded those} that were not

healthy black or

white adults

\section{Intervention/Exposure}

- MedDietScore, (modified

Panagiotakos, 2007):

o increasing intake of non-refined grains, fruits, vegetables, potatoes, legumes, fish, and olive oil (MUFA: SFA);

o decreasing intake of red meat, poultry, and full-fat dairy; moderate intake of alcohol.

- DASH score, (Folsom, 2007):

- Positive: whole grains, vegetables, fruit, low-fat dairy, legumes, and nuts:

- Negative: meat, fish and poultry, total fat, saturated fat, sweets, and sodium;

- A Priori Diet Quality Score (APDQS,

(Sjitmsa, 2012):

- Positive: fruit, vegetables, legumes, low-fat dairy, fish, moderate alcohol intake

- Adverse: fried foods, salty snacks, desserts, high-fat dairy, and sugar-sweetened soft drinks foods

- Neutral: lean meat, shellfish, potato eggs, chocolate, fruit juices, diet beverages

\section{Results}

- Low tertile: OR: 1, ref

- Mid tertile: OR: $0.66,95 \% \mathrm{Cl}: 0.51,0.85$

- High tertile: OR: $0.54,95 \% \mathrm{Cl}: 0.39,0.74$

DASH and cogntive function at $30 \mathrm{y} f / \mathrm{u}, \mathrm{NS}$

APDQS and cognitive function at $30 \mathrm{y} f / \mathrm{u}$

- $\quad$ per-SD increase: $\beta: 0.09,95 \% \mathrm{Cl}: 0.06$, 0.12

- Low tertile: OR: 1, ref

- Mid tertile: OR: 0.68, 95\% Cl: 0.52, 0.88

- High tertile: OR: 0.48, 95\% Cl: 0.33, 0.69

\section{Methodological Considerations}

Alcohol intake, Physical activity, Other:

diabetes, total energy intake

\section{Limitations:}

- Did not account for: Family history of NCD

- $\quad$ Large gaps between dietary data collection

Summary: Higher vs. lower MedDiet or APDQS adherence was significantly associated with less decline in cognitive function during $30 \mathrm{y} / \mathrm{u}$. No significant association between DASH score and cognitive function

Funding: Beeson-CARDI Fellowship from the American Federation of Aging Research; NHLBI; NIA

Diet assesed at baseline, year 7, and year 20 with diet history

\begin{tabular}{ll}
\hline Ozawa, 2017 & Reduced Rank Regression: \\
United Kingdom & $\begin{array}{l}\text { Response variables: serum IL-6 and } 37 \\
\text { food groups to derive the Inflammatory }\end{array}$ \\
Prospective & $\begin{array}{l}\text { Dietary Pattern Score, examined by } \\
\text { tertiles (T1, T2, T3) }\end{array}$ \\
\hline
\end{tabular}

Dietary pattern adherence and cognitive decline change over 10 y f/u:

Global cognitive score

- T2 vs. T1: ref.: $-0.35,95 \% \mathrm{Cl}:-0.37,-0.32$
Accounted for: Sex, Age, Race/ethnicity, SES: Occupation, Education, Anthropometry: BMI, Smoking, Physical activity, Other: Total energy intake, diabetes, hypertension 


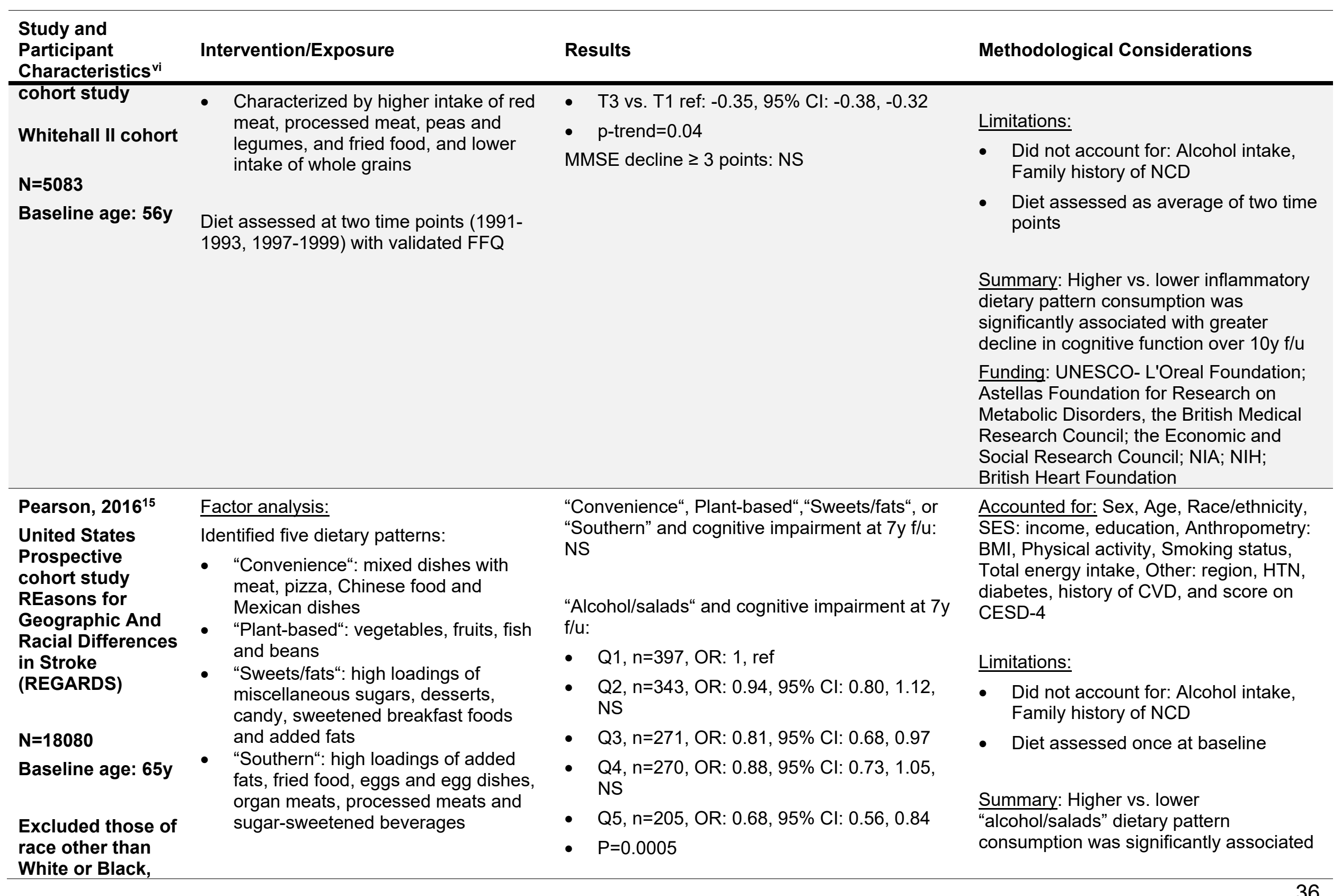




\begin{tabular}{|c|c|c|c|}
\hline $\begin{array}{l}\text { Study and } \\
\text { Participant } \\
\text { Characteristics }^{\mathrm{vi}}\end{array}$ & Intervention/Exposure & Results & Methodological Considerations \\
\hline $\begin{array}{l}\text { undergoing } \\
\text { treatment for } \\
\text { cancer or medical } \\
\text { conditions, } \\
\text { nursing home } \\
\text { residents, or non- } \\
\text { English users. } \\
\end{array}$ & $\begin{array}{l}\text { Alcohol/salads: high loadings of } \\
\text { green-leafy vegetables, tomatoes, } \\
\text { salad dressing, wine and liquor } \\
\text { Diet assesed once at baseline with } \\
\text { validated FFQ }\end{array}$ & & $\begin{array}{l}\text { with lower odds of cognitive decline at 7y } \\
\text { f/u } \\
\text { Funding: National Institute of Neurological } \\
\text { Disorders and Stroke, NIH, DHHS; } \\
\text { General Mills Bell Institute of Health and } \\
\text { Nutrition }\end{array}$ \\
\hline $\begin{array}{l}\text { Richard, } 2018 \\
\text { United States } \\
\text { Prospective } \\
\text { cohort study } \\
\text { Rancho Bernardo } \\
\text { Study } \\
\mathrm{N}=1499 \\
\text { Baseline age: } 73 \mathrm{y} \\
\text { Exclusions: }<50 \mathrm{y}\end{array}$ & 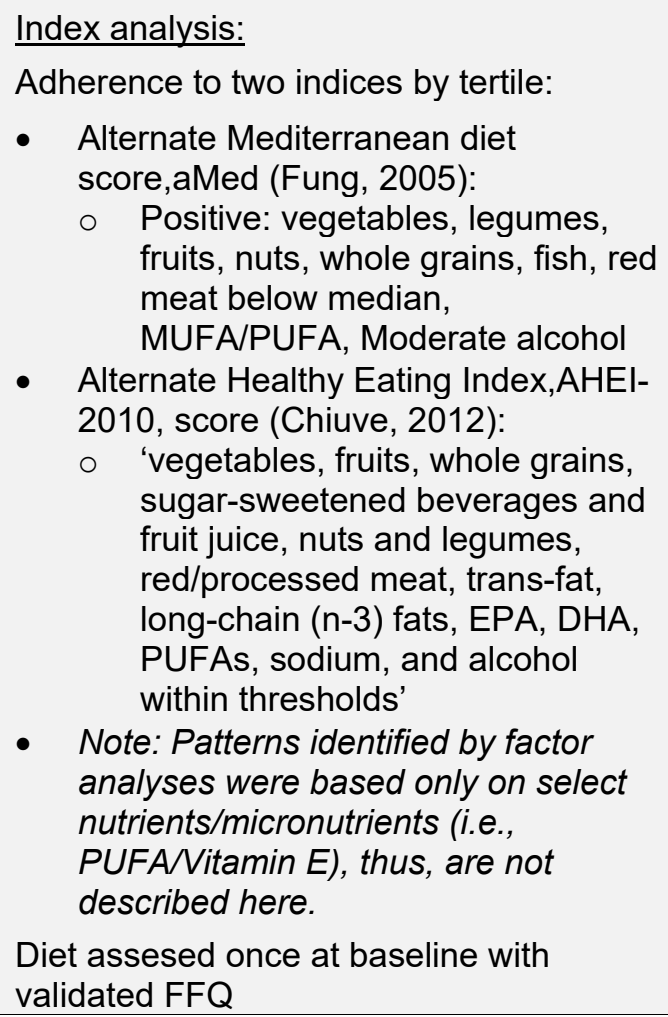 & 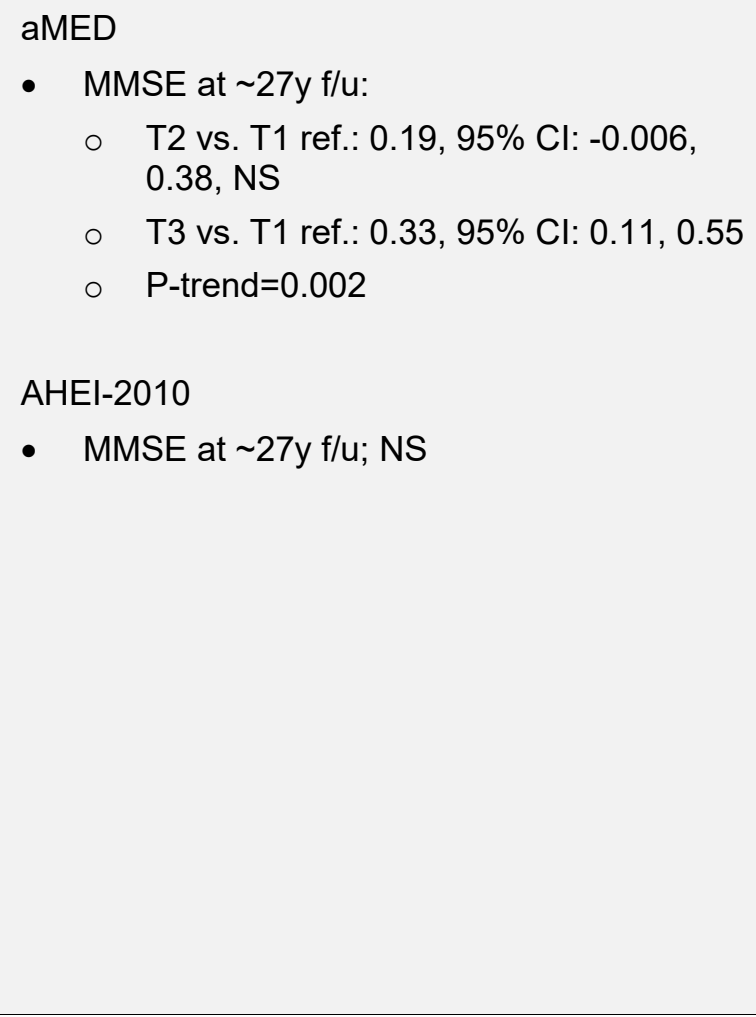 & $\begin{array}{l}\text { Limitations: } \\
\text { Did not account for: Race/ethnicity, } \\
\text { Physical activity, Anthropometry, } \\
\text { Family history of NCD } \\
\text { Diet was assessed once at baseline } \\
\text { with a FFQ } \\
\text { Summary: Higher vs. lower aMED } \\
\text { adherence dietary pattern consumption } \\
\text { was significantly associated with better } \\
\text { cognitive function. No significant } \\
\text { associations were identified for AHEI- } \\
\text { 2010 adherence and cognitive outcomes. } \\
\text { Funding: National Institute on Alcohol } \\
\text { Abuse and Alcoholism; NIA; National } \\
\text { Institute of Diabetes and Digestive and } \\
\text { Kidney Diseases }\end{array}$ \\
\hline $\begin{array}{l}\text { Shakersain, } \\
2016^{17} \\
\text { Sweden } \\
\text { Prospective }\end{array}$ & $\frac{\text { Factor analysis: }}{\text { Two dietary patterns were identified: }}$ & $\begin{array}{l}\text { "Western" and change in MMSE score over 6y } \\
\text { f/u: } \\
\text { - Continuous: } \beta:-0.045,95 \% \mathrm{Cl}:-0.071,- \\
0.019, p=0.001\end{array}$ & $\begin{array}{l}\text { Accounted for: Age, Sex, SES: Education, } \\
\text { Anthropometry: BMI, Smoking, Alcohol: } \\
\text { Part of dietary pattern, Physical activity, } \\
\text { Other: time, energy intake, civil status, }\end{array}$ \\
\hline
\end{tabular}




\section{Study and}

Participant

Characteristics $^{\text {vi }}$

cohort study

Swedish National

study on Aging

and Care-

Kungsholmen

(SNAC-K)

$\mathrm{N}=2223$

Baseline age: 71y

Excluded those

with dementia

\section{Intervention/Exposure}

- "Western": characterized by more frequent intakes of red/processed meat, saturated/trans-fat, refined grains, sugar, beer, and spirits

- "Prudent": characterized by more frequent intakes of vegetables, fruit, cooking/dressing oil, cereals and legumes, whole grains, rice/pasta, fish, low-fat dairy, poultry, and wate

Diet assessed once at baseline with validated FFQ

\section{Results}

- Q1: ref

- Q2: $\beta$ : $-0.075,95 \%$ Cl: $-0.154,0.004, N S$

- Q3: $\beta$ : $-0.137,95 \% \mathrm{Cl}:-0.217,-0.057$

- Q4: $\beta$ : $-0.063,95 \% \mathrm{Cl}:-0.144,0.017, \mathrm{NS}$

- Q5: $\beta$ : $-0.156,95 \% \mathrm{Cl}:-0.240,-0.073$

"Prudent" and change in MMSE score over 6y f/u:

- Continuous: $\beta$ : 0.043, 95\% Cl: 0.017, 0.068, $\mathrm{p}=0.001$

- Q1: ref

- Q2: $\beta: 0.001,95 \% \mathrm{Cl}:-0.085,0.083, \mathrm{NS}$

- Q3: $\beta$ : $0.061,95 \% \mathrm{Cl}:-0.021,0.143, \mathrm{NS}$

- Q4: $\beta: 0.122,95 \% \mathrm{Cl}: 0.039,0.204$

- Q5: $\beta: 0.106,95 \% \mathrm{Cl}: 0.024,0.189$

Similar results obtained when accounting for missing data with imputation,

\section{Methodological Considerations}

vitamin or mineral supplements, vascula

disorders, diabetes, cancer, depression, ApoE 4, and other dietary pattern.

Limitations:

- Did not account for: Race/ethnicity, Family history of NCD

- Diet assessed once at baseline

Summary: Higher vs. lower adherence to the "Prudent" dietary pattern at midlife was significantly associated with less MMSE decline at $6 y \mathrm{f} / \mathrm{u}$. Higher vs. lower adherence to the "Western" dietary pattern at midlife was significantly associated with more MMSE decline at 6y $\mathrm{f} / \mathrm{u}$, but was attenuated when accompanied by high "Prudent" dietary pattern adherence.

Funding: Ministry of Health and Social Affairs, Sweden; participating county councils and municipalities; Swedish Research Council for Health, Working Life and Welfare; Stiftelsen Ragnhild och Einar Lundstr€oms Minne; Gun och Bertil Stohnes Foundation; Demensfonden

\begin{tabular}{|c|c|}
\hline Shakersain, & $\underline{\text { Index analysis: }}$ \\
\hline $\begin{array}{l}2018 a^{18} \\
\text { Sweden }\end{array}$ & $\begin{array}{l}\text { Nordic Prudent Dietary Pattern score, } \\
\text { NPDP (Shakersain, 2018): }\end{array}$ \\
\hline $\begin{array}{l}\text { Prospective } \\
\text { cohort study } \\
\text { Swedish National }\end{array}$ & $\begin{array}{l}\text { Reflects high consumptions of non- } \\
\text { root vegetables, } \\
\text { apples/pears/peaches, pasta/rice, }\end{array}$ \\
\hline
\end{tabular}

NPDP adherence and change in MMSE over 6 y f/u:

- Low: T1: ref

- $\quad$ Moderate to High: $\beta$ : 0.19, 95\% Cl: 0.14, 0.24

- $\quad$ Moderate: $\beta$ : $0.14,95 \% \mathrm{Cl}: 0.08,0.20$
Accounted for: Age, Sex, SES: Education, Anthropometry: BMI, Smoking, Alcohol: Part of dietary pattern, Physical activity, Other: time, energy intake, civil status, vitamin/supplement use, vascular disorders, diabetes, cancer, depression, 


\section{Study and}

Participant

Characteristics $^{\text {vi }}$

study on Aging

and Care-

Kungsholmen

(SNAC-K)

\section{$\mathrm{N}=\mathbf{2 2 2 3}$}

Baseline age: $71 y$

Excluded those

with dementia

\section{Intervention/Exposure}

poultry, fish, vegetable oils (mainly

rapeseed oil), tea, and water, light to

moderate wine intake

- Reflects low consumptions of root

vegetables (including potatoes),

refined grains/cereals, high-fat dairy

products, butter/margarine,

sugar/sweets/pastries, and fruit juice.

\section{Results}

- High: $\beta$ : 0.24, 95\% Cl: 0.18, 0.30

- P-trend: <0.001

\section{Methodological Considerations}

ApoE 4, other dietary pattern, surviva status, social activity, mental activity

\section{Limitations:}

- Did not account for: Race/ethnicity Family history of NCD

- Diet assessed once at baseline

Summary: Higher vs. lower adherence to the Nordic Prudent dietary pattern in older adults was significantly associated with less MMSE decline at $6 y \mathrm{f} / \mathrm{u}$.

Funding: Ministry of Health and Social Affairs, Sweden; participating county councils and municipalities; Swedish Research Council; National Natural Science Foundation of China; Konung Gustaf V:s och Drottning Victorias Frimurare Foundation; Alzhermerfonden, and Demensfonden (Sweden);

Fondazione Umberto Veronesi; European Union's Horizon 2020 research and innovation programme

Shakersain,
2018b
Sweden
Prospective
cohort study
Swedish National
study on Aging
and Care-
Kungsholmen
(SNAC-K)

\section{Index analysis:}

- Nordic Prudent Dietary Pattern, NPDP: See Shakersain, 2018a

- MIND, hybrid Mediterranean DASH index (Morris, 2015): scored based on 10 brain healthy food groups: green leafy vegetables, other vegetables, nuts, berries, beans, whole grains, fish, poultry, olive oil and wine and 5 unhealthy food groups: red meats,
Diet indice/score adherence and rate of change in MMSE score over $6 \mathrm{y} / \mathrm{u}$ :

NPDP:

- Continuous: $\beta$ : $0.011,95 \% \mathrm{Cl}: 0.008,0.013$

- Low adherence, ref

- Moderate adherence: $\beta: 0.139,95 \% \mathrm{Cl}$ : $0.077,0.201$

- High adherence: $\beta: 0.238,95 \% \mathrm{Cl}: 0.175$, 0.300
Accounted for: Sex, Age, SES: Education, Anthropometry: BMI, Smoking, Alcohol: Part of dietary pattern, Physical activity, Other: Total calorie intake, civil status, vitamin/mineral supplementation, vascular disorders, diabetes, cancer, depression, APOE e4, dietary components other than those in each index

Limitations: 


\section{Study and}

Participant

Characteristics $^{\text {vi }}$
Baseline age: $71 y$

Excluded those with dementia.

\section{$\mathrm{N}=2223$}

Intervention/Exposure

butter/margarine, cheese, pastries

and sweets, and fried/fast food.

- MedDiet Score (Panagiotakos, 2007): Based on 11 items: non-refined cereals (whole grain bread and pasta, brown rice, etc), fruit, vegetables, legumes/beans, potatoes, fish, meat and meat products (red and processed meat), poultry, high-fat dairy products (like cheese, yoghurt, milk), as well as olive oil and alcohol (wine) intake.

- Dietary Approaches to Stop Hypertension, DASH (Morris, 2015): based on 10items: total grains /cereals, vegetables, fruits, dairy foods, meats/poultry/fish, legumes/beans, sugar/sweets/pastries; total fat, saturated fat and sodium.

- $\quad$ Baltic Sea Diet, BSD (Kanerva, 2014): Nordic vegetables: tomato, cucumber leafy vegetables, roots, cabbages, legumes; (ii) Nordic fruits: apples, pears, and berries; (iii) Nordic wholegrain cereals: rye, oats and barley; potatoes; low-fat and fat-free milk products; Nordic fish: salmon and freshwater fish; $E \%$ from fat, ratio of PUFA/SFA+Trans fat, red and processed meat: beef, pork, processed meat products and sausage; and sweets

$\begin{array}{lll}\text { Shannon, 201920 } & \text { Index analysis: } & \begin{array}{l}\text { Adherence to dietary pattern and global } \\ \text { cognition (SF-EMSE) during 14y f/u: }\end{array} \\ \text { United Kingdom } & \text { Mediterranean Diet Scores: } & \end{array}$

\section{Results}

MIND:

- Continuous: $\beta$ : 0.006, 95\% Cl: 0.003, 0.009

- Low adherence, ref

- $\quad$ Moderate adherence: $\beta: 0.075,95 \% \mathrm{Cl}$ : $0.012,0.138$

- High adherence: $\beta$ : 0.126, 95\% Cl: 0.064, 0.188

\section{MedDiet Score:}

- Continuous: $\beta$ : 0.006, 95\% Cl: 0.002, 0.009

- Low adherence, ref

- Moderate adherence: $\beta$ : 0.063, 95\% Cl: $0.002,0.129, \mathrm{NS}$

- High adherence: $\beta$ : 0.099, 95\% Cl: 0.036, 0.163

DASH:

- Continuous: NS

- Categorical: NS

\section{BSD:}

Continuous: $\beta$ : 0.006, 95\% Cl: 0.002, 0.009

- Categorical: NS

\section{Methodological Considerations}

- Did not account for: Race/ethnicity Family history of NCD

- $\quad$ Diet assessed once at baseline

Summary: Higher vs. lower adherence (both continuously and categorically) to the Nordic Prudent dietary pattern, the MIND pattern, and MedDiet score in older adults was significantly associated with less MMSE decline at $6 y \mathrm{f} / \mathrm{u}$. There was no significant relationship between DASH adherence and MMSE decline at $6 \mathrm{y} / \mathrm{u}$. Higher adherence to the Baltic Sea Diet was only significantly associated continuously with less MMSE decline at $6 y \mathrm{f} / \mathrm{u}$.

Funding: Ministry of Health and Social Affairs, Sweden; participating county councils and municipalities; the Swedish Research Council; the National Natural Science Foundation of China; European Union's Horizon 2020 research and innovation programme; the Konung Gustaf V:s och Drottning Victorias Frimurare Foundation; Diabetes

Foundation; Gun och Bertil Stohnes Foundation; Alzheimerfonden; and the Dementia Association (Sweden)

Accounted for: Age, Sex, SES: Marita status, Employment, Education, Anthropometry: BMI and Waist 


\begin{tabular}{|c|c|c|c|}
\hline $\begin{array}{l}\text { Study and } \\
\text { Participant } \\
\text { Characteristics vi }\end{array}$ & Intervention/Exposure & Results & Methodological Considerations \\
\hline $\begin{array}{l}\text { Prospective } \\
\text { cohort study } \\
\text { EPIC-Norfolk } \\
\mathrm{N}=8009 \\
\text { Baseline age: } 55 \mathrm{y}\end{array}$ & $\begin{array}{l}\text { Mediterranean Diet Adherence } \\
\text { Screener, MEDAS (Papadaki, 2018): } \\
\text { categorical and continuous score } \\
\text { O Positive: Vegetables, Legumes, } \\
\text { Fruit, Nuts, Seafood, Olive Oil, } \\
\text { Olive oil as principal cooking fat } \\
\text { More white meat than red meat, } \\
\text { Wine, Sofrito (lasagne) } \\
\text { - Negative: Sweets or pastries, Red } \\
\text { Meat or Sausages (including } \\
\text { lasagne), Sugar-Sweetened } \\
\text { Beverages, Butter, margarine, or } \\
\text { cream (including low-fat } \\
\text { spread)MedDiet Pyramid (Tong, } \\
\text { 2016): continuous score } \\
\text { Positive: Vegetables, Legumes, } \\
\text { Fruit, Nuts, Cereals, Fish, White } \\
\text { meat, Eggs, Olive Oil } \\
\text {. Moderate: Alcohol } \\
\text { Negative: Potato, Red meat, } \\
\text { Processed meat, Sweets }\end{array}$ & $\begin{array}{l}\text { - MEDAS: } \beta \text { : }-0.004, \text { SE: } 0.002 \\
\text { - MEDAS Continuous: } \beta \text { : }-0.005, \text { SE: } 0.002 \\
\text { - } \text { MedDiet Pyramid: per-1-point increase: } \beta \text { : - } \\
0.012, P<0.001\end{array}$ & $\begin{array}{l}\text { Circumference, Smoking, Physical } \\
\text { activity, Other: Self-reported medical } \\
\text { conditions, self-reported medications, } \\
\text { HDL and LDL cholesterol, total } \\
\text { triglycerides, DBP, SBP, APOE E4 } \\
\text { Limitations: } \\
\text { - Did not account for: Race/ethnicity, } \\
\text { Alcohol intake, Family history of NCD } \\
\text { Dietary intake evaluated once at } \\
\text { baseline } \\
\text { Summary: Higher adherence to all three } \\
\text { MedDiet scores was significantly } \\
\text { associated with better performance on } \\
\text { global cognition during } 14 y \text { f/u in middle- } \\
\text { aged adults. There was no significant } \\
\text { association with the MedDiet scores and } \\
\text { performance in retrospective memory, } \\
\text { attention, or complex processing speed. } \\
\text { MedDiet Pyramid adherence score was } \\
\text { significantly associated with better } \\
\text { performance in simple processing speed } \\
\text { and retrospective memory, but the other } \\
\text { two scores were not. } \\
\text { Funding: Alzheimer's Research UK } \\
\text { Prevention and Risk Reduction Fund }\end{array}$ \\
\hline $\begin{array}{l}\text { Smyth, } 2015^{21} \\
40 \text { Countries } \\
\text { Prospective } \\
\text { cohort study } \\
\text { 'ONTARGET and } \\
\text { TRANSCEND' }\end{array}$ & $\begin{array}{l}\text { Index analysis: } \\
\text { Modified Alternative Healthy Eating Index } \\
\text { (AHEI) score (Dehghan, 2012) } \\
\text { components, within specified limits: } \\
\text { - Vegetable, Fruits, Nuts and soy } \\
\quad \text { proteins, Whole grain, Deep-fried }\end{array}$ & $\begin{array}{l}\text { Adherence to AHEl and cognitive decline over } 5 \\
\text { y f/u: } \\
\text { - Q1: ref } \\
\text { - Q2, Q3, Q4 vs. Q1 ref. NS } \\
\text { - Q5 vs. Q1 ref.: HR: } 0.76,95 \% \mathrm{Cl}: 0.66,0.86\end{array}$ & $\begin{array}{l}\text { Accounted for: Sex, Age, SES: Education, } \\
\text { Anthropometry: BMI, Smoking, Alcohol: } \\
\text { Part of dietary pattern, Physical activity, } \\
\text { Other: trial enrollment, treatment } \\
\text { allocation, geographical region, baseline } \\
\text { MMSE score, SBP, history of stroke/TIA, } \\
\text { DM, MI, microalbuminuria, } \\
\text { macroalbuminuria, serum creatinine, }\end{array}$ \\
\hline
\end{tabular}




\section{Study and}

Participant

$\mathrm{N}=\mathbf{2 7 8 6 0}$

Baseline age: $66 y$
Characteristics $^{\text {vi }}$

Intervention/Exposure

foods, Ratio of fish to meat and egg

Alcohol

(a)

\section{Tomata, $2016^{22}$ \\ Japan \\ Prospective \\ cohort study \\ $\mathrm{N}=14402$}

Baseline age: $74 y$

Excluded those that did not

provide consent

for review of their

long-term care

insurance

information, those

that had a

disability before

starting f/u, those

that died or

\section{Factor analysis:}

- 'Japanese' pattern - loaded heavily on fish, vegetables, mushrooms, potato, seaweeds, pickles, soybean, and fruits

- 'Animal food' pattern - loaded heavily on various animal-derived foods (beef, pork, ham, sausage, chicken, liver, egg, and butter)

- 'High-dairy' pattern - heavily loaded on dairy products (yoghurt, cheese, and butter), margarine, and black tea, Chinese tea, and negatively loaded on rice.

\section{Results}

Subgroup analysis:

- Excluding early cases in $<2 \mathrm{y} f / \mathrm{u}$, composite outcomes, MMSE<24 at baseline, or those with cancer at baseline yeilded similar results

- Stratification by MMSE score at baseline: Increased adherence to the AHEI was significantly associated with a reduced cognitive decline when MMSE was 26-28 or $>28$ at baseline, but MMSE $<26$ was NS.

- Stratification by physical activity status at baseline: Increased adherence in AHEI was significantly associated with a reduced cognitive decline with moderate or high activity at baseline, but not sedentary.

'Japanese' pattern score and dementia over 6 y $\mathrm{f} / \mathrm{u}$ :

- Q1: ref

- Q2 or Q3 vs. Q1 ref: NS

- Q4 vs. Q1 ref: HR: $0.80,95 \% \mathrm{Cl}: 0.66,0.97$

'Animal food' pattern and dementia over 6 y f/u: NS

'High-dairy' pattern and dementia over 6 y f/u: NS

\section{Methodological Considerations}

statin therapy, beta-blocker therapy, antithrombotic use, depression.

\section{Limitations:}

- Did not account for: Race/ethnicity, Family history of NCD

Summary: Higher adherence to the mAHEI was significantly associated with less cognitive decline during $5 y \mathrm{f} / \mathrm{u}$, both overall and in those with MMSE 26-28 or $>28$ at baseline, as well as those with moderate or high physical activity at baseline.

Funding: Boehringer Ingelheim

Accounted for: Sex, Age, SES: Education, Anthropometry: BMI, Smoking, Alcohol, Physical activity, Other: history of nonNCD chronic disease, psychological distress score, motor function score, number of remaining teeth, cognitive function score, energy intake, protein intake

\section{Limitations:}

- Did not account for: Race/ethnicity, Family history of NCD

Summary: Higher adherence to the 'Japanese dietary pattern' was significantly associated with reduced dementia risk in older Japanese adults over a $6 \mathrm{y} f / u$. There was no significant association between the 'animal food' 


\begin{tabular}{|c|c|c|c|}
\hline $\begin{array}{l}\text { Study and } \\
\text { Participant } \\
\text { Characteristics }^{\mathrm{vi}}\end{array}$ & Intervention/Exposure & Results & Methodological Considerations \\
\hline \multirow{2}{*}{$\begin{array}{l}\text { moved before the } \\
\text { start of f/u, and } \\
\text { those for which a } \\
\text { doctor's opinion } \\
\text { paper was } \\
\text { unavailable }\end{array}$} & & & $\begin{array}{l}\text { pattern or 'high-dairy' pattern and } \\
\text { dementia risk. }\end{array}$ \\
\hline & & & $\begin{array}{l}\text { Funding: Honjo International Scholarship } \\
\text { Foundation; Health Sciences Research } \\
\text { grants from the Ministry of Health, Labour } \\
\text { and Welfare of Japan }\end{array}$ \\
\hline Voortman, $2017^{23}$ & $\underline{\text { Index analysis: }}$ & \multirow{7}{*}{$\begin{array}{l}\text { Adherence to Dutch Dietary guidelines score } \\
\text { and risk of dementia over } 12 \mathrm{y} / \mathrm{u} \text { : NS }\end{array}$} & Accounted for: Sex, Age, SES: Education, \\
\hline Netherlands & $\begin{array}{l}\text { Dutch dietary guidelines score }-2015 \\
\text { (Voortman, 2017): }\end{array}$ & & $\begin{array}{l}\text { Anthropometry: BMI, Smoking, Alcohol: } \\
\text { Part of dietary pattern, Physical activity, } \\
\text { Other: Cohort total enerav intake }\end{array}$ \\
\hline \multirow{5}{*}{$\begin{array}{l}\text { Prospective } \\
\text { cohort study } \\
\text { Rotterdam Study } \\
\mathrm{N}=9701 \\
\text { Baseline age: } 64 \mathrm{y}\end{array}$} & \multirow{5}{*}{$\begin{array}{l}\text { Positive components: Vegetables, } \\
\text { legumes, fruit, nuts, whole grains, } \\
\text { fish, dairy products, unsaturated fats } \\
\text { and oils, tea } \\
\text { Negative components: Replace } \\
\text { refined grains with whole-grain } \\
\text { products, red meat, processed meat, } \\
\text { alcohol, sodium }\end{array}$} & & Limitations: \\
\hline & & & - Did not account for: Race/ethnicity, \\
\hline & & & - Diet assessed once at baseline \\
\hline & & & $\begin{array}{l}\text { Summary: Higher adherence to the Dutch } \\
\text { Dietary Guidelines score by an older } \\
\text { Dutch population over } 12 \text { y f/u was not } \\
\text { significantly associated with a reduced } \\
\text { risk of dementia. }\end{array}$ \\
\hline & & & $\begin{array}{l}\text { Funding: Erasmus University Medical } \\
\text { Center and Erasmus University } \\
\text { Rotterdam; Netherlands Organization for } \\
\text { Health Research and Development; } \\
\text { Research Institute for Diseases in the } \\
\text { Elderly; Netherlands Genomics Initiative; } \\
\text { Ministry of Education, Culture and } \\
\text { Science; Ministry of Health, Welfare and } \\
\text { Sports; European Commission; } \\
\text { Municipality of Rotterdam. }\end{array}$ \\
\hline $\begin{array}{l}\text { Wagner, } 2019^{24} \\
\text { United States }\end{array}$ & $\begin{array}{l}\text { Index analysis: } \\
\text { alternate Mediterranean diet, A-MeDi } \\
\text { (Cheng, } 2018 \text { modified Fung, 2005) score }\end{array}$ & $\begin{array}{l}\text { A-MeDi score in cases of cognitive decline }(10 \% \\
\text { worst TICS slopes) remained lower than } \\
\text { controls at } 1 \mathrm{y} \text { f/u: mean difference }-0.19,95 \% \\
\mathrm{Cl}:-0.29,-0.09 \text {. }\end{array}$ & $\begin{array}{l}\text { Accounted for: Sex, Age, SES: Education, } \\
\text { Anthropometry: BMI part of design, } \\
\text { Alcohol: Part of dietary pattern, Physical } \\
\text { activity: part of design }\end{array}$ \\
\hline
\end{tabular}




\begin{tabular}{|c|c|c|c|}
\hline $\begin{array}{l}\text { Study and } \\
\text { Participant } \\
\text { Characteristics }^{\mathrm{vi}}\end{array}$ & Intervention/Exposure & Results & Methodological Considerations \\
\hline $\begin{array}{l}\text { Nested Case- } \\
\text { Control } \\
\text { Nurses' Health } \\
\text { Study (NHS) } \\
\text { N=1496 cases, } \\
7478 \text { controls } \\
100 \% \text { female, } \\
\text { Baseline age: } \\
\sim 61 \mathrm{y}\end{array}$ & $\begin{array}{l}\text { Positive components: Vegetables, } \\
\text { legumes, fruit, nuts, whole grains, } \\
\text { fish, MUFA:SFA ratio } \\
\text { - } \text { Moderate: Alcohol } \\
\text { - Negative components: red/processed } \\
\text { meat }\end{array}$ & & $\begin{array}{l}\text { Limitations: } \\
\text { - Did not account for: Race/ethnicity, } \\
\quad \text { Smoking, Family history of NCD } \\
\text { Summary: Cases of cognitive decline } \\
\text { compared to controls had lower } \\
\text { adherence to A-MeDi. } \\
\text { Funding: NIH }\end{array}$ \\
\hline $\begin{array}{l}\text { Wu, } 2019^{25} \\
\text { Singapore } \\
\text { Prospective } \\
\text { cohort study } \\
\text { Singapore } \\
\text { Chinese Health } \\
\text { Study } \\
\mathrm{N}=16948 \\
\text { Baseline age: } \\
53.5 y \\
\\
\text { Excluded those } \\
\text { with cancer or } \\
\text { CVD at baseline }\end{array}$ & $\begin{array}{l}\text { Index analysis: } \\
\text { - } \quad \text { alternate Mediterranean diet (aMED) } \\
\text { score (Fung, 2005): positively scored } \\
\text { vegetables (not potatoes), fruit, } \\
\text { legumes, nuts, whole grains, fish, } \\
\text { MUFA/SFA, and moderate alcohol; } \\
\text { negatively scored red and processed } \\
\text { meat } \\
\text { Dietary Approaches to Stop } \\
\text { Hypertension (DASH) diet (modified } \\
\text { Fung, 2008: positively scored } \\
\text { vegetables (not potatoes), fruit and } \\
\text { fruit juice, legumes and nuts, whole } \\
\text { grains, and total dairy; negatively } \\
\text { scored red and processed meat, } \\
\text { sugar-sweetened beverages, and } \\
\text { sodium } \\
\text { alternative Healthy Eating Index } \\
\text { (AHEI)-2010 score (adjusted Chiuve, } \\
\text { 2012): positively scored vegetables } \\
\text { (not potatoes, French fries), fruit, } \\
\text { legumes and nuts, whole grains, long- } \\
\text { chain fats and PUFA, and moderate } \\
\text { alcohol; negatively scored red and }\end{array}$ & 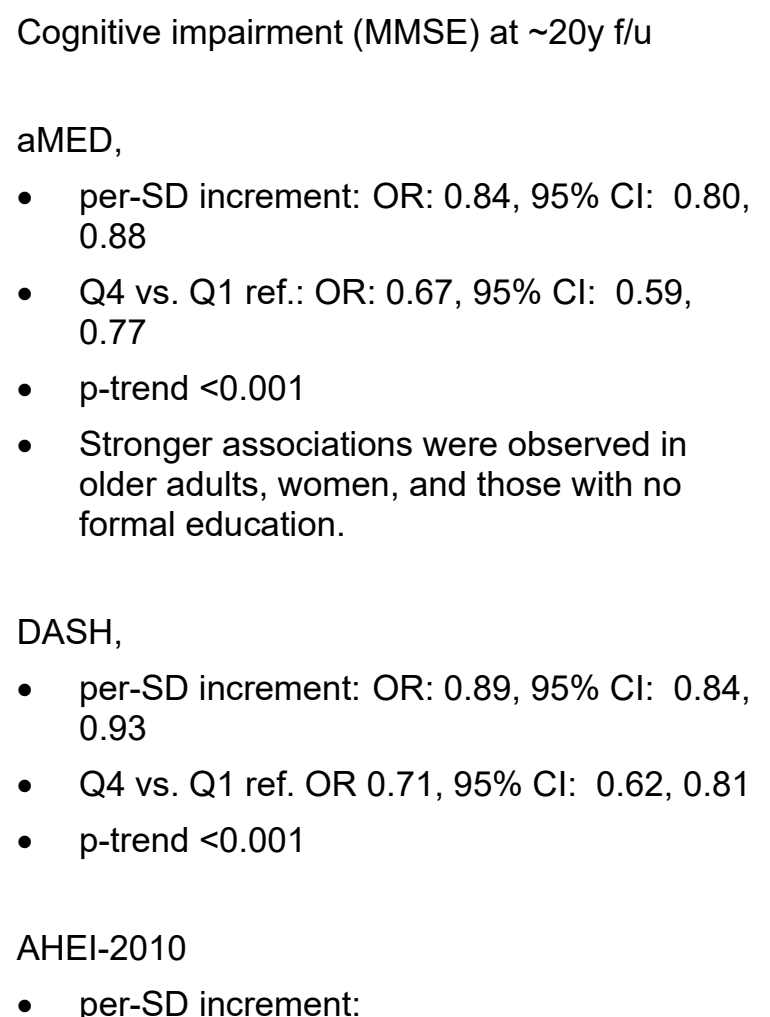 & $\begin{array}{l}\text { Limitations: } \\
\text { - Did not account for: Race/ethnicity, } \\
\text { Family history of NCD } \\
\text { - Diet assessed once at baseline } \\
\text { Summary: Higher vs. lower adherence to } \\
\text { all dietary pattern indices examined } \\
\text { (aMED, DASH, AHEI-2010, PDI, hPDI) } \\
\text { was significantly associated with lower } \\
\text { risk of cognitive impairment at 20y f/u. } \\
\text { Funding: National Medical Research } \\
\text { Council, Singapore; NIH; Saw Swee Hock } \\
\text { School of Public Health, National } \\
\text { University of Singapore; National Key } \\
\text { Research and Development Program of }\end{array}$ \\
\hline
\end{tabular}




\section{Study and}

Participant

Characteristics $^{\text {vi }}$

\section{Methodological Considerations}

processed meat, sugar-sweetened beverages and fruit juice, trans fat, and sodium

- Plant-based diet index (PDI) (Satija, 2016): positively scored "all plant foods" and negatively scored "animal foods"

- Healthful plant-based diet index (hPDI) (Satija, 2016): positively scored "healthy plant foods" and negatively scored "less healthy plant foods"

Diet assessed once at baseline with validated FFQ

- Q4 vs. Q1 ref. OR $0.75,95 \% \mathrm{Cl}: 0.66,0.85$

- $p$-trend $<0.001$

- Stronger associations were observed in women

PDI

- per-SD increment: OR: $0.89,95 \% \mathrm{Cl}: 0.85$, 0.94

- Q4 vs. Q1 ref. OR 0.82, 95\% Cl: $0.71,0.94$

- $\quad$-trend $<0.001$

hPDI

Distinguished Young Scholars
- per-SD increment: OR: $0.93,95 \% \mathrm{Cl}: 0.88$, 0.97

- Q4 vs. Q1 ref. OR 0.78, 95\% Cl: $0.68,0.90$

- $\quad$-trend $<0.001$

- Stronger associations were observed in those with no formal education

In overall sub-analyses, associations were not significantly modified by sex, education level, BMI group, baseline hypertension, or diabetes.

Zhu, 2015
United States
Prospective
cohort study
CARDIA
$\mathrm{N}=2435$

Index analysis:

A Priori Diet Quality Score, APDQS

(Sjitsma, 2012)

- Positive: fruit, vegetables, legumes, low-fat dairy, fish, coffee/tea, moderate alcohol intake

- Adverse: fried foods, high fat meat, salty snacks, desserts, high-fat dairy, and sugar-sweetened soft drinks
APDQS per 10-unit increase at baseline APDQS and RAVLT at 25y f/u: Slope $=0.16$, $p=0.004$; DSST: NS; higher; Stroop: NS

APDQS per 10-unit increase at 20y and RAVLT at $25 \mathrm{y} / \mathrm{u}$ : Slope $=0.21, \mathrm{p}=0.0003$; DSST: Slope $=0.82, p=0.002$; Stroop: Slope $=-0.58$, $p=0.007$
China; Hubei Province Science Fund for

$\mathrm{N}=\mathbf{2 4 3 5}$
Accounted for: Age, Sex, Race, SES:

Education, Anthropometry: BMI, Physical activity, Alcohol: Part of dietary pattern, Smoking, Other: study center, energy intake, blood pressure, total cholesterol, diabetes, apoE4

Limitations:

- Did not account for: N/A 


\section{Study and}

Participant

Characteristics $^{\text {vi }}$

Baseline age: 18.

$30 y$

$52 \%$ African-

American, $48 \%$

white

Intervention/Exposure

Results

APDQS per 10-unit increase change from baseline-20y f/u and RAVLT at 25y f/u:

eggs, chocolate, fruit juices, diet

beverages

Slope $=0.16, p=0.01 ;$ DSST: Slope $=0.70$, $p=0.01$; Stroop: Slope $=-0.55, p=0.02$

Diet assessed twice, once at baseline and once at f/u with CARDIA study diet history

\section{Methodological Considerations}

- $\quad$ Diet assessment at two time points span 20y

Summary: Higher vs. lower APDQS

adherence at $20 \mathrm{y}$ f/u or dietary change from baseline to $20 \mathrm{y} f / \mathrm{u}$ was significantly associated with better cognitive test results at 25y f/u.

Funding: NHLBI; NIA 
Table 3. Risk of bias for randomized controlled trials examining dietary patterns and cognitive impairment, dementia, or Alzheimer's disease ${ }^{\text {vii, viii }}$

\begin{tabular}{|c|c|c|c|c|c|c|}
\hline & Randomization & $\begin{array}{c}\text { Deviations from } \\
\text { intended interventions } \\
\text { - effect of assignment }\end{array}$ & $\begin{array}{c}\text { Deviations from } \\
\text { intended interventions- } \\
\text { per-protocol }\end{array}$ & $\begin{array}{l}\text { Missing } \\
\text { outcome data }\end{array}$ & $\begin{array}{c}\text { Outcome } \\
\text { measurement }\end{array}$ & $\begin{array}{l}\text { Selection of } \\
\text { reported result }\end{array}$ \\
\hline Chlebowski, $2020^{1}$ & Low & Low & Low & Low & Some concerns & Some concerns \\
\hline Knight, 2016 3 & Low & Low & Low & Low & Low & Some concerns \\
\hline Marseglia, 2018² & Some concerns & Low & Low & Low & Low & Some concerns \\
\hline Valls-Pedret, $2015^{4}$ & Some concerns & Low & Low & Low & Low & Some concerns \\
\hline
\end{tabular}

vii A detailed description of the methodology used for assessing risk of bias is available on the NESR website: https://nesr.usda.gov/2020-dietaryguidelines-advisory-committee-systematic-reviews and in Part C of the following reference: Dietary Guidelines Advisory Committee. 2020. Scientific Report of the 2020 Dietary Guidelines Advisory Committee: Advisory Report to the Secretary of Agriculture and the Secretary of Health and Human Services. U.S. Department of Agriculture, Agricultural Research Service, Washington, DC.

viii Possible ratings of low, some concerns, or high determined using the "Cochrane Risk-of-bias 2.0" (RoB 2.0) (August 2016 version)" (Higgins JPT,

Sterne JAC, Savović J, Page MJ, Hróbjartsson A, Boutron I, Reeves B, Eldridge S. A revised tool for assessing risk of bias in randomized trials In:

Chandler J, McKenzie J, Boutron I, Welch V (editors). Cochrane Methods. Cochrane Database of Systematic Reviews 2016, Issue 10 (Suppl 1).

dx.doi.org/10.1002/14651858.CD201601.) 
Table 4. Risk of bias for observational studies examining dietary patterns and cognitive impairment, dementia, or Alzheimer's disease ${ }^{i x}$

\begin{tabular}{|c|c|c|c|c|c|c|c|}
\hline & Confounding & $\begin{array}{l}\text { Selection of } \\
\text { participants }\end{array}$ & $\begin{array}{l}\text { Classification } \\
\text { of exposures }\end{array}$ & $\begin{array}{c}\text { Deviations from } \\
\text { intended exposures }\end{array}$ & Missing data & $\begin{array}{c}\text { Outcome } \\
\text { measurement }\end{array}$ & $\begin{array}{c}\text { Selection of } \\
\text { reported result }\end{array}$ \\
\hline Adjibade, $2019^{5}$ & Serious & Serious & Low & Serious & Moderate & Low & Serious \\
\hline Akbaraly, 20196 & Serious & Moderate & Low & Moderate & Moderate & Low & Moderate \\
\hline Berendsen, $2017^{7}$ & Serious & Moderate & Low & Moderate & Moderate & Low & Serious \\
\hline Berendsen, $2018^{8}$ & Serious & Moderate & Low & Moderate & Moderate & Low & Serious \\
\hline Bhushan, 20189 & Serious & Moderate & Low & Moderate & Serious & Low & Moderate \\
\hline $\begin{array}{l}\text { Dearborn-Tomazos, } \\
2019^{10}\end{array}$ & Serious & Serious & Low & Serious & Serious & Low & Moderate \\
\hline Haring, 2016 ${ }^{11}$ & Serious & Moderate & Low & Serious & Moderate & Low & Moderate \\
\hline Mannikko, $2015^{12}$ & Serious & Serious & Low & Moderate & Serious & Low & Moderate \\
\hline McEvoy, $2019^{13}$ & Serious & Moderate & Low & Moderate & Serious & Low & Moderate \\
\hline Ozawa, $2017^{14}$ & Serious & Serious & Low & Moderate & Serious & Low & Moderate \\
\hline Pearson, 2016 ${ }^{15}$ & Serious & Serious & Low & Serious & Serious & Moderate & Moderate \\
\hline Richard, $2018^{16}$ & Serious & Moderate & Low & Moderate & Serious & Low & Low \\
\hline Shakersain, $2016^{17}$ & Serious & Serious & Low & Moderate & Serious & Low & Moderate \\
\hline Shakersain, 2018a ${ }^{18}$ & Serious & Serious & Low & Moderate & Serious & Low & Serious \\
\hline Shakersain, 2018b ${ }^{19}$ & Serious & Serious & Low & Moderate & Serious & Low & Moderate \\
\hline Shannon, $2019^{20}$ & Serious & Moderate & Low & Serious & $\begin{array}{c}\text { No } \\
\text { Information }\end{array}$ & Low & Moderate \\
\hline Smyth, 201521 & Serious & Serious & Low & Moderate & Serious & Low & Moderate \\
\hline Tomata, $2016^{22}$ & Serious & Serious & Low & Moderate & Moderate & Low & Moderate \\
\hline Voortman, $2017^{23}$ & Serious & Serious & Moderate & Serious & Moderate & Low & Moderate \\
\hline Wagner, 2019²4 & Serious & Serious & Low & Serious & Moderate & Serious & Moderate \\
\hline Wu, 201925 & Serious & Moderate & Low & Moderate & Moderate & Low & Moderate \\
\hline Zhu, $2015^{26}$ & Moderate & Moderate & Low & Serious & Serious & Low & Moderate \\
\hline
\end{tabular}

ix Possible ratings of low, moderate, serious, critical, or no information determined using the "Risk of Bias for Nutrition Observational Studies" tool (RoBNObs) (Dietary Guidelines Advisory Committee. 2020. Scientific Report of the 2020 Dietary Guidelines Advisory Committee: Advisory Report to the Secretary of Agriculture and the Secretary of Health and Human Services. U.S. Department of Agriculture, Agricultural Research Service, Washington, DC.) 
The NESR team used its rigorous, protocol-driven methodology to support the 2020 Dietary Guidelines Advisory Committee in conducting this update to an existing systematic review.

NESR's systematic review methodology involves:

- Developing a protocol,

- Searching for and selecting studies,

- Extracting data from and assessing the risk of bias of each included study,

- Synthesizing the evidence,

- Developing conclusion statements,

- Grading the evidence underlying the conclusion statements, and

- Recommending future research.

A detailed description of the methodology used in conducting this update to an existing systematic review is available on the NESR website: https://nesr.usda.gov/2020-dietaryguidelines-advisory-committee-systematic-reviews, and can be found in 2020 Dietary Guidelines Advisory Committee Report, Part C: Methodology. ${ }^{x}$ This systematic review was peer reviewed by Federal scientists, and information about the peer review process can also be found in the Committee's Report, Part C. Methodology. Additional information about this systematic review, including a description of and rationale for any modifications made to the protocol can be found in the 2020 Dietary Guidelines Advisory Committee Report, Part D: Chapter 8. Dietary Patterns.

The systematic review described in this document updates an existing systematic review conducted by the 2015 Dietary Guidelines Advisory Committee with support from USDA's Nutrition Evidence Systematic Review (NESR) team. Information about the 2015 Dietary Guidelines Advisory Committee's review of the evidence on dietary patterns and cancer can be found in their report, which is available at the following website:

https://nesr.usda.gov/dietary-patterns-foods-and-nutrients-and-health-outcomessubcommittee and https://www.dietaryguidelines.gov/current-dietary-guidelines/processdevelop-2015-2020-dg/advisory-committee

Below are details of the final protocol, as it was applied to the systematic review described herein, including the:

- Analytic framework

- Literature search and screening plan

- Literature search and screening results

\section{ANALYTIC FRAMEWORK}

The analytic framework (Figure 1) illustrates the overall scope of this update to an existing systematic review, including the population, the interventions and/or exposures, comparators, and outcomes of interest. It also includes definitions of key terms and

x Dietary Guidelines Advisory Committee. 2020. Scientific Report of the 2020 Dietary Guidelines Advisory Committee: Advisory Report to the Secretary of Health and Human Services and the Secretary of Agriculture. U.S. Department of Agriculture, Agricultural Research Service, Washington, DC. 
identifies key confounders and other factors considered in the systematic review. The inclusion and exclusion criteria that follow provide additional information about how parts of the analytic framework were defined and operationalized for the review.

\section{Figure 1: Analytic framework}

Systematic review question: What is the relationship between dietary patterns consumed and neurocognitive health?

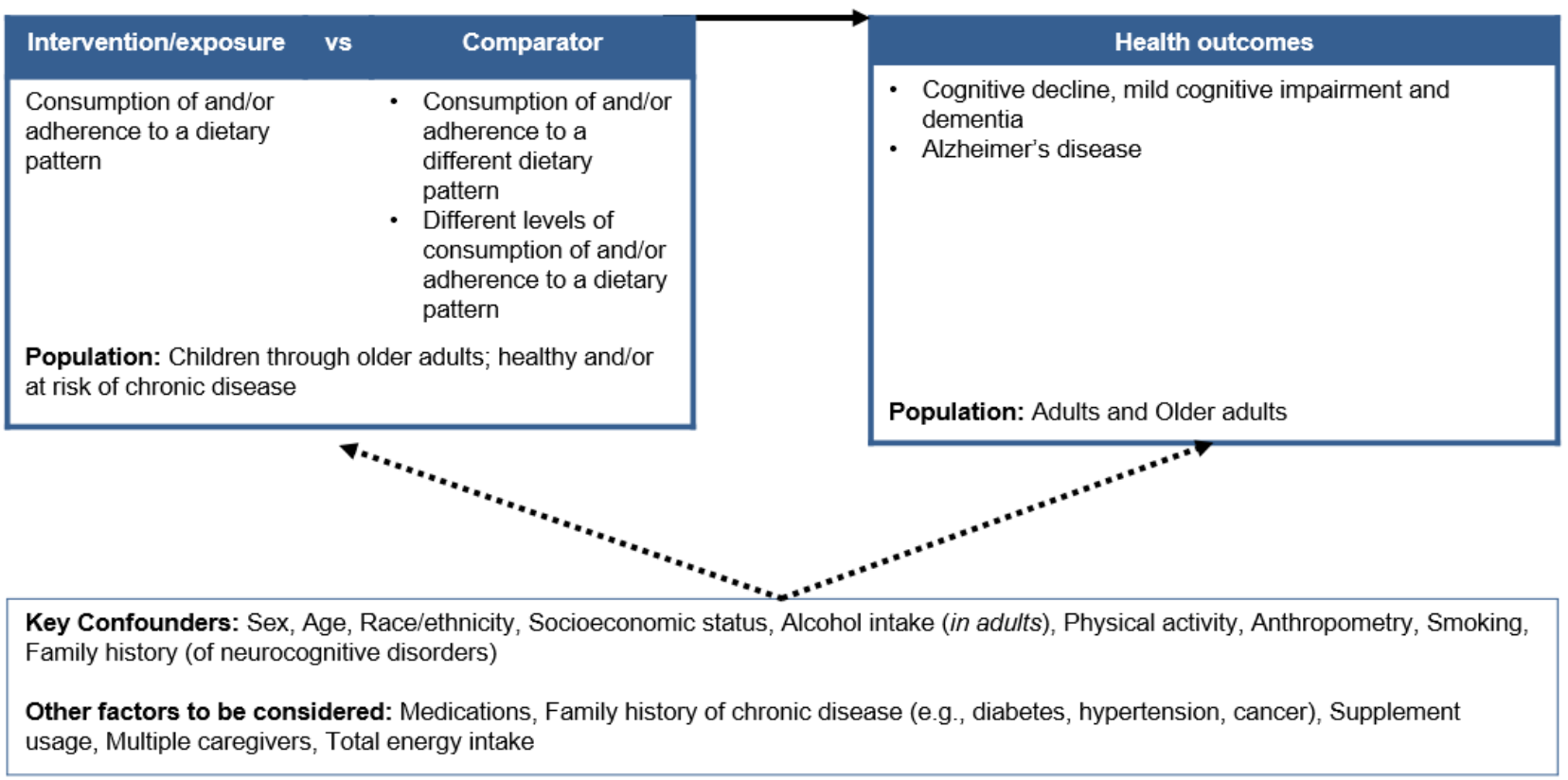

Key definitions

Dietary patterns - The quantities, proportions, variety, or combination of different foods, drinks, and nutrients (when available) in diets, and the frequency with which they are habitually consumed

\section{Legend}

$\longrightarrow$ The relationship of interest in the systematic review Factors that may impact the relationship of interest in the systematic review

\section{LITERATURE SEARCH AND SCREENING PLAN}

\section{Inclusion and exclusion criteria}

This table provides the inclusion and exclusion criteria for this update to an existing systematic review. The inclusion and exclusion criteria are a set of characteristics that were used to determine which articles identified in the literature search were included in or excluded from the systematic review. 
Table 5. Inclusion and exclusion criteria

\begin{tabular}{|c|c|c|}
\hline Category & Inclusion Criteria & Exclusion Criteria \\
\hline Study design & $\begin{array}{l}\text { - } \quad \text { Randomized controlled trials } \\
\text { - } \quad \text { Non-randomized controlled trials, including } \\
\text { quasi-experimental and controlled before } \\
\text { and after studies } \\
\text { - } \quad \text { Prospective cohort studies } \\
\text { - } \quad \text { Retrospective cohort studies } \\
\text { - } \quad \text { Nested case-control studies }\end{array}$ & $\begin{array}{l}\text { - Uncontrolled trials } \\
\text { - } \quad \text { Cross-sectional studies } \\
\text { - } \quad \text { Uncontrolled before-and-after studies } \\
\text { - } \quad \text { Narrative reviews } \\
\text { - } \quad \text { Systematic reviews } \\
\text { - } \quad \text { Meta-analyses } \\
\text { - } \quad \text { Case-control studies }\end{array}$ \\
\hline $\begin{array}{l}\text { Intervention/ } \\
\text { exposure }\end{array}$ & $\begin{array}{l}\text { Studies that examine consumption of } \\
\text { and/or adherence to a dietary pattern [i.e., } \\
\text { the quantities, proportions, variety, or } \\
\text { combination of different foods, drinks, and } \\
\text { nutrients (when available) in diets, and the } \\
\text { frequency with which they are habitually } \\
\text { consumed], including, at a minimum, a } \\
\text { description of the foods and beverages in } \\
\text { the pattern } \\
\text { Dietary patterns may be measured or } \\
\text { derived using a variety of approaches, } \\
\text { such as adherence to a priori patterns } \\
\text { (indices/scores), data driven patterns } \\
\text { (factor or cluster analysis), reduced } \\
\text { rank regression, or other methods, } \\
\text { including clinical trials }\end{array}$ & $\begin{array}{l}\text { - Studies that do not provide a description of } \\
\text { the dietary pattern, which at minimum, must } \\
\text { include the foods and beverages in the } \\
\text { pattern (i.e., studies that examine a labeled } \\
\text { dietary pattern, but do not describe the foods } \\
\text { and beverages consumed) }\end{array}$ \\
\hline Comparator & $\begin{array}{l}\text { - Consumption of and/or adherence to a } \\
\text { different dietary pattern } \\
\text { - Different levels of consumption of and/or } \\
\text { adherence to a dietary pattern }\end{array}$ & - $\quad \mathrm{N} / \mathrm{A}$ \\
\hline Outcomes & $\begin{array}{l}\text { - Cognitive decline, mild cognitive } \\
\text { impairment, and dementia } \\
\text { - Alzheimer's disease }\end{array}$ & \\
\hline $\begin{array}{l}\text { Date of } \\
\text { publication }\end{array}$ & $\begin{array}{l}\text { August } 2014-\text { February } 2020 \text { (this date } \\
\text { range is in addition to the original } \\
\text { systematic review, which included articles } \\
\text { published from January 1980-August 2014) }\end{array}$ & $\begin{array}{l}\text { - Articles published prior to January } 1980 \text { or } \\
\text { after February } 2020\end{array}$ \\
\hline $\begin{array}{l}\text { Publication } \\
\text { status }\end{array}$ & Articles that have been peer-reviewed & $\begin{array}{l}\text { Articles that have not been peer-reviewed and } \\
\text { are not published in peer-reviewed journals (e.g., } \\
\text { unpublished data, manuscripts, reports, } \\
\text { abstracts, pre-prints, and conference } \\
\text { proceedings) }\end{array}$ \\
\hline $\begin{array}{l}\text { Language of } \\
\text { publication }\end{array}$ & Articles published in English & $\begin{array}{l}\text { Articles published in languages other than } \\
\text { English }\end{array}$ \\
\hline
\end{tabular}




\begin{tabular}{|c|c|c|}
\hline Category & Inclusion Criteria & Exclusion Criteria \\
\hline Country ${ }^{x i}$ & $\begin{array}{l}\text { Studies conducted in countries ranked as high } \\
\text { or higher human development }\end{array}$ & $\begin{array}{l}\text { Studies conducted in countries ranked as } \\
\text { medium or lower human development }\end{array}$ \\
\hline $\begin{array}{l}\text { Study } \\
\text { participants }\end{array}$ & $\begin{array}{l}\text { - Human participants } \\
\text { - Males } \\
\text { - Females } \\
\text { - Women during pregnancy and lactation }\end{array}$ & - Non-human participants (i.e., animals) \\
\hline $\begin{array}{l}\text { Age of study } \\
\text { participants }\end{array}$ & 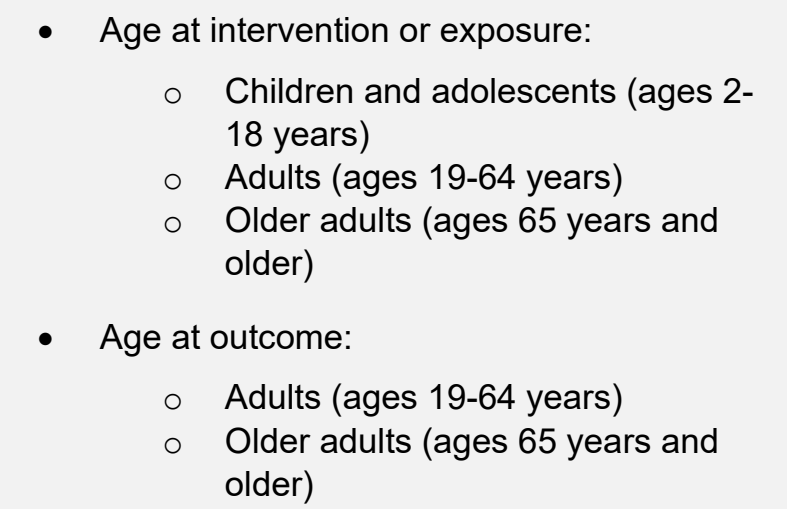 & $\begin{array}{l}\text { - Age at intervention or exposure: } \\
\quad \begin{array}{l}\text { Infants and toddlers (birth to } 24 \\
\text { months) }\end{array} \\
\text { - Age at outcome: } \\
\circ \quad \begin{array}{l}\text { Infants and toddlers (birth to } 24 \\
\text { months) }\end{array}\end{array}$ \\
\hline $\begin{array}{l}\text { Study } \\
\text { duration }\end{array}$ & - Minimum length of intervention of 12 weeks & - Interventions $<12$ weeks \\
\hline $\begin{array}{l}\text { Size of study } \\
\text { groups }\end{array}$ & $\begin{array}{l}\text { - } 30 \text { participants per-arm for interventions, or } \\
\text { - } \quad \text { A power calculation included for interventions } \\
\text { - } \mathrm{n} \geq 1,000 \text { for observational studies }\end{array}$ & $\begin{array}{l}\text { - Fewer than } 30 \text { participants per arm for } \\
\text { interventions, or } \\
\text { - } \quad \text { No power calculation reported for } \\
\text { interventions } \\
\text { - Fewer than } 1000 \text { participants for } \\
\text { observational studies }\end{array}$ \\
\hline
\end{tabular}

xi The Human Development classification was based on the Human Development Index (HDI) ranking from the year the study intervention occurred or data were collected (UN Development Program. HDI 1990-2017 HDRO calculations based on data from UNDESA (2017a), UNESCO Institute for Statistics (2018), United Nations Statistics Division (2018b), World Bank (2018b), Barro and Lee (2016) and IMF (2018). Available from: http://hdr.undp.org/en/data). If the study did not report the year in which the intervention occurred or data were collected, the HDI classification for the year of publication was applied. HDI values are available from 1980, and then from 1990 to present. If a study was conducted prior to 1990, the HDI classification from 1990 was applied. If a study was conducted in 2018 or 2019 , the most current HDI classification was applied. When a country was not included in the HDI ranking, the current country classification from the World Bank was used instead (The World Bank. World Bank country and lending groups. Available from: https://datahelpdesk.worldbank.org/knowledgebase/articles/ 906519 -world- country-and-lending-groups). 


\begin{tabular}{lll}
\hline Category & Inclusion Criteria & \multicolumn{2}{c}{ Exclusion Criteria } \\
\hline $\begin{array}{l}\text { Health status } \\
\text { of study } \\
\text { participants }\end{array}$ & $\begin{array}{l}\text { Studies that enroll participants who are healthy } \\
\text { and/or at risk for chronic disease, including those } \\
\text { with obesity }\end{array}$ & $\begin{array}{l}\text { Studies that exclusively enroll } \\
\text { participants diagnosed with a disease or } \\
\text { hospitalized with illness or injury. (For this } \\
\text { criterion, studies that exclusively enroll } \\
\text { subjects with obesity will be included.) }\end{array}$ \\
& $\begin{array}{l}\text { Studies that enroll some participants diagnosed } \\
\text { with a disease }\end{array}$ & $\begin{array}{l}\text { Studies that exclusively enroll } \\
\text { participants with mild cognitive } \\
\text { impairment, dementia, or Alzheimer's } \\
\text { disease (i.e., studies that aim to treat } \\
\text { participants who have already been } \\
\text { diagnosed with the outcome of interest) }\end{array}$ \\
& $\begin{array}{l}\text { Studies that enroll some participants diagnosed } \\
\text { with mild cognitive impairment, dementia, or } \\
\text { Alzheimer's disease }\end{array}$ &
\end{tabular}

\section{Electronic databases and search strategy}

Listed below are the databases searched to identify all potentially relevant articles that have been published to address this update to an existing systematic review.

\section{PubMed}

- Provider: U.S. National Library of Medicine

- Date(s) Searched: February 4, 2020

- Date range searched: January 1, 2014 - February 4, 2020

- Search Terms:

\#1 - dietary pattern* OR diet pattern* OR eating pattern* OR food pattern* OR diet quality* OR eating habit* OR dietary habit* OR diet habit* OR food habit* OR beverage habit* OR "Feeding Behavior"[Mesh:NoExp] OR feeding behavior*[tiab] OR dietary profile* OR food profile* OR diet profile* OR eating profile* OR dietary guideline* OR dietary recommendation* OR dietary intake* OR eating style* OR "Diet, Mediterranean"[Mesh] OR Mediterranean Diet*[tiab] OR "Dietary Approaches To Stop Hypertension"[Mesh] OR Dietary Approaches To Stop Hypertension Diet* OR DASH diet* OR "Diet, Gluten-Free"[Mesh] OR Gluten Free diet* OR prudent

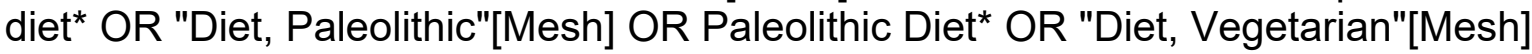
OR vegetarian diet*[tiab] OR vegan diet* $^{*}$ OR "Diet, Healthy"[Mesh] OR healthy diet* OR plant based diet* OR "Diet, Western"[Mesh] OR western diet* OR "Diet, Carbohydrate-Restricted"[Mesh] OR low-carbohydrate diet* OR high carbohydrate diet $^{*}$ OR Ketogenic Diet* OR Nordic Diet* OR "Diet, Fat-Restricted"[Mesh] OR "Diet, High-Fat"[Mesh] OR "Diet, High-Protein"[Mesh] OR high protein diet*[tiab] OR protein intake ${ }^{*}$ OR high-fat diet* OR low fat diet* OR "Diet, ProteinRestricted"[Mesh] OR low protein $\operatorname{diet}^{*}$ OR "Diet, Sodium-Restricted"[Mesh] OR lowsodium diet* OR low salt diet* OR (“"Guideline Adherence"[Mesh] OR guideline adherence*) AND (diet[tiab] OR dietary[tiab] OR food[tiab] OR beverage*[tiab] OR nutrition*[tiab])) OR diet score* OR diet quality score* OR diet quality index* OR kidmed OR diet index* OR dietary index* OR food score* OR MedDietScore OR healthy eating index[tiab] OR ((pattern[tiab] OR patterns[tiab] OR consumption[tiab] OR habit*[tiab]) AND ("Diet"[Mesh:NoExp] OR diet[tiab] OR diets[tiab] OR dietary[tiab] OR "Food"[Mesh] OR food[tiab] OR foods[tiab] OR "Beverages"[Mesh] 
OR beverage[tiab] OR beverages[tiab]))

\#2 - "Cognition Disorders"[Mesh] OR "Cognition"[Mesh] OR cognition[tiab] OR metacognition[tiab] OR neurocognitive[tiab] OR "Dementia"[Mesh] OR dementia[tiab] OR Alzheimer*[tiab] OR senility[tiab] OR senile[tiab] OR presenile[tiab] OR (cognit*[tiab] AND (function*[tiab] OR dysfunction*[tiab] OR declin*[tiab] OR deteriorat* OR degenerat*[tiab] OR disorder*[tiab] OR dysfunction*[tiab] OR reduct*[tiab] OR impair*[tiab] OR deficit*[tiab] OR deficien* OR progress* $\left[\right.$ tiab] OR perform ${ }^{\star}[$ tiab] OR abilit*[tiab]))

\#3 - (\#1 AND \#2)

\#4 - (\#1 AND \#2) NOT ("Animals"[Mesh] NOT ("Animals"[Mesh] AND "Humans"[Mesh])) NOT (editorial[ptyp] OR comment[ptyp] OR news[ptyp] OR letter[ptyp] OR review[ptyp] OR systematic review[ptyp] OR systematic review[ti] OR meta-analysis[ptyp] OR meta-analysis[ti] OR meta-analyses[ti] OR retracted publication[ptyp] OR retraction of publication[ptyp] OR retraction of publication[tiab] OR retraction notice[ti]) Filters: Publication date from 2014/01/01 to 2020/02/04; English

\section{Cochrane Central Register of Controlled Trials (CENTRAL)}

- Provider: John Wiley \& Sons

- Date(s) Searched: February 4, 2020

- Date range searched: January 1, 2014 - February 4, 2020

- Search Terms:

\#1 - [mh ^"Feeding Behavior"] OR [mh "Diet, Mediterranean"] OR [mh "Dietary Approaches To Stop Hypertension"] OR [mh "Diet, Gluten-Free"] OR [mh "Diet, Paleolithic"] OR [mh "Diet, Vegetarian"] OR [mh "Diet, Healthy"] OR [mh "Diet, Western"] OR [mh "Diet, Carbohydrate-Restricted"] OR [mh "Diet, Fat-Restricted"] OR [mh "Diet, High-Fat"] OR [mh "Diet, High-Protein"] OR [mh "Diet, ProteinRestricted"] OR [mh "Diet, Sodium-Restricted"]

\#2 - ("dietary pattern*" OR "diet pattern*" OR "eating pattern*" OR "food pattern*" OR "diet quality*" OR "eating habit*" OR "dietary habit*" OR "diet habit*" OR "food habit" OR "beverage habit"" OR "feeding behavior" OR "dietary profile*" OR "food profile*" OR "diet profile*" OR "eating profile*" OR "dietary guideline ${ }^{* "}$ OR "dietary recommendation*" OR "dietary intake*" OR "eating style*" OR "Mediterranean Diet" OR "Dietary Approaches To Stop Hypertension Diet"" OR "DASH diet" OR "Gluten Free diet" OR "prudent diet" OR "Paleolithic Diet" OR "vegetarian diet" OR "vegan diet*" OR "healthy diet*" OR "plant based diet*" OR "western diet*" OR "lowcarbohydrate diet" OR "high carbohydrate diet" OR "Ketogenic Diet*" OR "Nordic Diet $^{\star "}$ OR "high protein diet*" OR "protein intake*" OR "high-fat diet*" OR "low fat diet" $^{* "}$ OR "low protein diet" OR "low-sodium diet*" OR "low salt diet"):ti,ab,kw

\#3 - (([mh "Guideline Adherence"] OR guideline adherence*) NEAR/6 (diet OR dietary OR food OR beverage* OR nutrition*))

\#4 - ("diet score*" OR "diet quality score*" OR "diet quality index*" OR kidmed OR "diet index" OR "dietary index*" OR "food score*" OR MedDietScore OR "healthy eating index*"):ti,ab,kw 
\#5 - ((pattern OR patterns OR consumption OR habit*) NEAR/6 ([mh ^"Diet"] OR diet OR diets OR dietary OR [mh "Food"] OR food OR foods OR [mh "Beverages"] OR beverage OR beverages))

\#6 - \#1 OR \#2 OR \#3 OR \#4 OR \#5

\#7 - [mh "Cognition Disorders"] OR [mh "Cognition"] OR [mh "Dementia"]

\#8 - (cognition OR metacognition OR neurocognitive OR dementia OR Alzheimer* OR senility OR senile OR presenile):ti,ab,kw

\#9 - ((cognit* NEAR/6 (function* OR dysfunction* OR declin* OR deteriorat* OR degenerat* OR disorder* OR dysfunction* OR reduct* OR impair* OR deficit* OR deficien* OR progress ${ }^{*}$ OR perform* OR abilit*))):ti,ab,kw

\section{\#10 - \#7 OR \#8 OR \#9}

\#11 - \#6 AND \#10" with Publication Year from 2014 to 2020, in Trials (Word variations have been searched)

\section{Embase}

- Provider: Elsevier

- Date(s) Searched: February 4, 2020

- Date range searched: January 1, 2014 - February 4, 2020

- Search Terms:

\#1 - 'feeding behavior'/de OR 'mediterranean diet'/exp OR 'dash diet'/exp OR 'gluten free diet'/exp OR 'paleolithic diet'/de OR 'vegetarian diet'/exp OR 'healthy diet'/exp OR 'western diet'/de OR 'low carbohydrate diet'/exp OR 'low fat diet'/de OR 'lipid diet'/exp OR 'protein diet'/exp OR 'protein restriction'/exp OR 'sodium restriction'/exp

\#2 - 'dietary pattern'':ab,ti OR 'diet pattern*':ab,ti OR 'eating pattern*':ab,ti OR 'food pattern"':ab,ti OR 'diet quality*':ab,ti OR 'eating habit"':ab,ti OR 'dietary habit' OR 'diet habit': ab,ti OR 'food habit*':ab,ti OR 'beverage habit' ${ }^{*}$ :ab,ti OR 'feeding behavior*':ab,ti OR 'dietary profile*':ab,ti OR 'food profile ${ }^{* \prime}: a b, t i$ OR 'diet profile*':ab,ti OR 'eating profile ${ }^{* \prime}: a b, t i$ OR 'dietary guideline ${ }^{* 1}: a b, t i$ OR 'dietary recommendation ${ }^{*}: a b, t i$ OR 'dietary intake ${ }^{* \prime}: a b, t i$ OR 'eating style ${ }^{* \prime}: a b, t i$ OR 'mediterranean diet"':ab,ti OR 'dietary approaches to stop hypertension diet $^{* \prime}: a b, t i$ OR 'dash diet ${ }^{\star \prime}: a b, t i$ OR 'gluten free diet $^{\star \prime}: a b$, ti OR 'prudent diet ${ }^{\star \prime}: a b, t i$ OR 'paleolithic diet"':ab,ti OR 'vegetarian diet $^{* \prime}: a b, t i$ OR 'vegan $\operatorname{diet}^{* 1}:$ ab,ti OR 'healthy diet':ab,ti OR 'plant based diet*':ab,ti OR 'western diet $^{\star \prime}: a b$, ti OR 'low-carbohydrate $\operatorname{diet}^{* \prime}: a b, t i$ OR 'high carbohydrate diet $^{* \prime}: a b$,ti OR 'ketogenic diet ${ }^{\star *}: a b, t i$ OR 'nordic $\operatorname{diet}^{* 1}: a b, t i$ OR 'high protein $\operatorname{diet}^{* \prime}: a b, t i$ OR 'protein intake ${ }^{* \prime}: a b, t i$ OR 'high-fat $\operatorname{diet}^{* 1}: a b, t i$ OR 'low fat diet*':ab,ti OR 'low protein $\operatorname{diet}^{* \prime}: a b, t i$ OR 'low-sodium $\operatorname{diet}^{* \prime}: a b, t i$ OR 'low salt $\operatorname{diet}^{* \prime}: a b, t i$

\#3 - ('guideline adherence*' NEAR/6 (diet OR dietary OR food OR beverage* OR nutrition*)):ab,ti

\#4 - 'diet score*':ab,ti OR 'diet quality score ${ }^{* 1}:$ ab,ti OR 'diet quality index"':ab,ti OR kidmed:ab,ti OR 'diet index"':ab,ti OR 'dietary index':ab,ti OR 'food score':ab,ti OR 
meddietscore:ab,ti OR 'healthy eating index*':ab,ti

\#5 - ((pattern OR patterns OR consumption OR habit*) NEAR/6 (diet OR diets OR dietary OR food OR foods OR beverage OR beverages)):ab,ti

\#6 - \#1 OR \#2 OR \#3 OR \#4 OR \#5

\#7 - 'cognitive defect'/exp OR 'cognition'/exp OR 'dementia'/exp

\#8 - cognition:ab,ti OR metacognition:ab,ti OR neurocognitive:ab,ti OR dementia:ab,ti OR alzheimer*:ab,ti OR senility:ab,ti OR senile:ab,ti OR presenile:ab,ti

\#9 - (cognit* NEAR/6 (function* OR dysfunction* OR declin* OR deteriorat* OR degenerat* OR disorder* OR dysfunction* OR reduct* OR impair* OR deficit* OR deficien* OR progress* ${ }^{*}$ OR perform* ${ }^{*}$ OR abilit*)):ab,ti

\#10 - \#7 OR \#8 OR \#9

\#11 - \#6 AND \#10

\#12 - \#6 AND \#10 AND ([article]/lim OR [article in press]/lim) AND [humans]/lim AND [english]/lim AND [2014-2020]/py NOT ([conference abstract]/lim OR [conference paper]/lim OR [conference review]/lim OR [editorial]/lim OR [erratum]/lim OR [letter]/lim OR [note]/lim OR [review]/lim OR [systematic review]/lim OR [meta analysis]/lim) 


\section{LITERATURE SEARCH AND SCREENING RESULTS}

The flow chart (Figure 2) below illustrates the literature search and screening results for articles examining the update to this systematic review question. The results of the electronic database searches, after removal of duplicates, were screened independently by two NESR analysts using a step-wise process by reviewing titles, abstracts, and full-texts to determine which articles met the inclusion criteria. Refer to Table $\mathbf{6}$ for the rationale for exclusion for each excluded full-text article. A manual search was done to find articles that were not identified when searching the electronic databases; all manually identified articles were also screened to determine whether they meet criteria for inclusion.

Figure 2: Flow chart of literature search and screening results

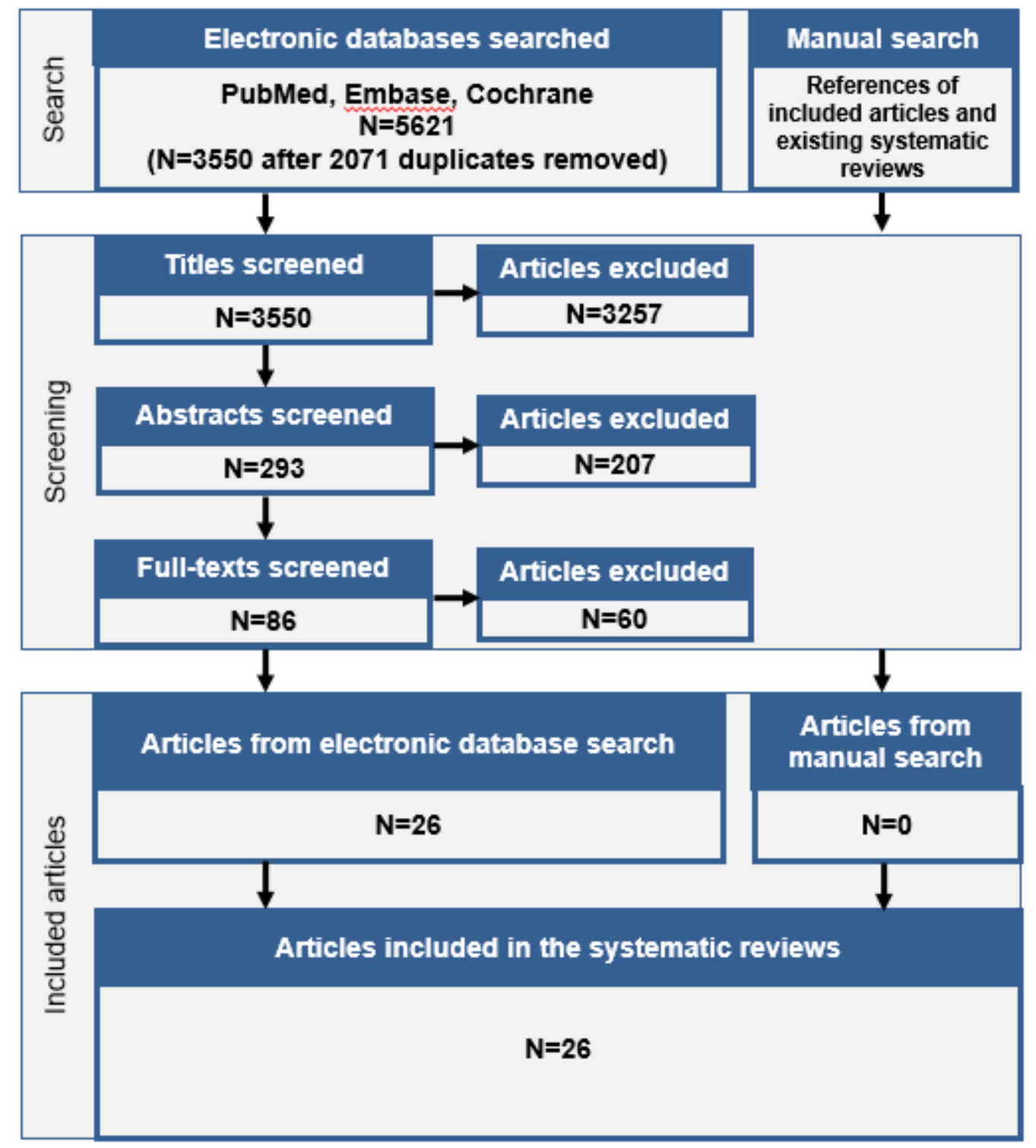




\section{Excluded Articles}

The table below lists the articles excluded after full-text screening for the update to this systematic review question. At least one reason for exclusion is provided for each article, though this may not reflect all possible reasons. Information about articles excluded after title and abstract screening is available upon request.

\section{Table 6. Articles excluded after full text screening with rationale for exclusion}

\section{Citation}

1 Alavi-Naeini, A, Bagheri, M, Mirzaei, K, Maljaei, MB, Yekaninejad, MS, Yazdani, A. Relationship between dietary patterns and mild cognitive impairment (MCl) in elderly women. Progress in Nutrition. 2019. 21:270-280. doi:10.23751/pn.v21i1-S.6090

2 Anastasiou, CA, Yannakoulia, M, Kontogianni, MD, Kosmidis, MH, Mamalaki, E, Dardiotis, E, Hadjigeorgiou, G, Sakka, P, Tsapanou, A, Lykou, A, Scarmeas, N. Mediterranean Lifestyle in Relation to Cognitive Health: Results from the HELIAD Study. Nutrients. 2018. 10. doi:10.3390/nu10101557

3 Anastasiou, CA, Yannakoulia, M, Kosmidis, MH, Dardiotis, E, Hadjigeorgiou, GM, Sakka, P, Arampatzi, X, Bougea, A, Labropoulos, I, Scarmeas, N. Mediterranean diet and cognitive health: Initial results from the Hellenic Longitudinal Investigation of Ageing and Diet. PLoS One. 2017. 12:e0182048. doi:10.1371/journal.pone.0182048

4 Ashby-Mitchell, K, Peeters, A, Anstey, KJ. Role of dietary pattern analysis in determining cognitive status in elderly Australian adults. Nutrients. 2015. 7:1052-67. doi:10.3390/nu7021052

5 Assmann, KE, Adjibade, M, Adriouch, S, Andreeva, VA, Julia, C, Hercberg, S, Galan, P, Kesse-Guyot, E. Association of diet quality and physical activity with healthy ageing in the French NutriNet-Sante cohort. Br J Nutr. 2019. 122:93-102. doi:10.1017/s0007114519000898

6 Assmann, KE, Adjibade, M, Andreeva, VA, Hercberg, S, Galan, P, Kesse-Guyot, E. Association Between Adherence to the Mediterranean Diet at Midlife and Healthy Aging in a Cohort of French Adults. J Gerontol A Biol Sci Med Sci. 2018. 73:347-354. doi:10.1093/gerona/glx066

7 Assmann, KE, Andreeva, VA, Camilleri, GM, Verger, EO, Jeandel, C, Hercberg, S, Galan, P, Kesse-Guyot, E. Dietary scores at midlife and healthy ageing in a French prospective cohort. Br J Nutr. 2016. 116:666-76. doi:10.1017/s0007114516002233

8 Assmann, KE, Lassale, C, Andreeva, VA, Jeandel, C, Hercberg, S, Galan, P, Kesse-Guyot, E. A Healthy Dietary Pattern at Midlife, Outcome Combined with a Regulated Energy Intake, Is Related to Increased Odds for Healthy Aging. J Nutr. 2015. 145:2139-45. doi:10.3945/jn.115.210740

9 Bajerska, J, Wozniewicz, M, Suwalska, A, Jeszka, J. Eating patterns are associated with cognitive function in the elderly at risk of Power/ Size metabolic syndrome from rural areas. Eur Rev Med Pharmacol Sci. 2014. 18:3234-45. doi: unavailable

10 Blumenthal, JA, Smith, PJ, Mabe, S, Hinderliter, A, Welsh-Bohmer, K, Browndyke, JN, Doraiswamy, PM, Lin, PH, Kraus, WE, Burke, JR, Sherwood, A. Longer Term Effects of Diet and Exercise on Neurocognition: 1-Year Follow-up of the ENLIGHTEN Trial. J Am Geriatr Soc. 2019. doi:10.1111/jgs.16252
Rationale

Study Design Power/ Size

Study Design

Study Design

Power/ Size

Outcome

Outcome

Outcome

Health Status 
11 Chan, R, Leung, J, Woo, J. Dietary patterns and risk of frailty in Chinese community-dwelling older people in Hong Kong: A prospective cohort study. Nutrients. 2015. 7:7070-7084. doi:10.3390/nu7085326

Study Design

Chen, YC, Jung, CC, Chen, JH, Chiou, JM, Chen, TF, Chen, YF, Tang, SC, Yeh, SJ, Lee, MS. Association of Dietary Patterns Outcome

With Global and Domain-Specific Cognitive Decline in Chinese Elderly. J Am Geriatr Soc. 2017. 65:1159-1167.

Power/ Size doi:10.1111/jgs.14741

13 Cheung, BHK, Ho, ICH, Chan, RSM, Sea, MMM, Woo, J. Current evidence on dietary pattern and cognitive function. 2014. 71:137-163. doi:10.1016/B978-0-12-800270-4.00004-3

14 Chou, YC, Lee, MS, Chiou, JM, Chen, TF, Chen, YC, Chen, JH. Association of Diet Quality and Vegetable Variety with the Risk of Power/ Size Cognitive Decline in Chinese Older Adults. Nutrients. 2019. 11. doi:10.3390/nu11071666

15 Chuang, SY, Lo, YL, Wu, SY, Wang, PN, Pan, WH. Dietary Patterns and Foods Associated With Cognitive Function in Taiwanese Country Older Adults: The Cross-sectional and Longitudinal Studies. J Am Med Dir Assoc. 2019. 20:544-550.e4. doi:10.1016/j.jamda.2018.10.017

16 Diener, HC. Multidimensional prevention of dementia diseases. MMW Fortschritte der Medizin. $2015.157: 39$. doi:10.1007/s15006-015-3658-1

17 Feng, Z, Cramm, JM, Nieboer, AP. A healthy diet and physical activity are important to promote healthy ageing among older Chinese people. Journal of International Medical Research. 2019. 47:6061-6081. doi:10.1177/0300060519882590

18 Ferrand, C, Féart, C, Martinent, G, Albinet, C, André, N, Audiffren, M. Dietary patterns in French home-living older adults: Results from the PRAUSE study. Archives of Gerontology and Geriatrics. 2017. 70:180-185. doi:10.1016/j.archger.2017.01.015

19 Galbete, C, Toledo, E, Toledo, JB, Bes-Rastrollo, M, Buil-Cosiales, P, Marti, A, Guillen-Grima, F, Martinez-Gonzalez, MA. Mediterranean diet and cognitive function: the SUN project. J Nutr Health Aging. 2015. 19:305-12. doi:10.1007/s12603-015-0441Z

20 Gallucci, M, Pallucca, C, Di Battista, ME, Fougere, B, Grossi, E. Artificial Neural Networks Help to Better Understand the Interplay Between Cognition, Mediterranean Diet, and Physical Performance: Clues from TRELONG Study. J Alzheimers Dis. 2019. 71:1321-1330. doi:10.3233/jad-190609

21 Gardener, SL, Rainey-Smith, SR, Barnes, MB, Sohrabi, HR, Weinborn, M, Lim, YY, Harrington, K, Taddei, K, Gu, Y, Rembach, A, Power/ Size Szoeke, C, Ellis, KA, Masters, CL, Macaulay, SL, Rowe, CC, Ames, D, Keogh, JB, Scarmeas, N, Martins, RN. Dietary patterns and cognitive decline in an Australian study of ageing. Mol Psychiatry. 2015. 20:860-6. doi:10.1038/mp.2014.79

22 Gopinath, B, Russell, J, Kifley, A, Flood, VM, Mitchell, P. Adherence to Dietary Guidelines and Successful Aging Over 10 Years. J Outcome Gerontol A Biol Sci Med Sci. 2016. 71:349-55. doi:10.1093/gerona/glv189

23 Gougeon, L, Payette, H, Morais, J, Gaudreau, P, Shatenstein, B, Gray-Donald, K. Dietary patterns and incidence of depression in Outcome a cohort of community-dwelling older Canadians. J Nutr Health Aging. 2015. 19:431-6. doi:10.1007/s12603-014-0562-9

24 Granic, A, Davies, K, Adamson, A, Kirkwood, T, Hill, TR, Siervo, M, Mathers, JC, Jagger, C. Dietary Patterns High in Red Meat, Potato, Gravy, and Butter Are Associated with Poor Cognitive Functioning but Not with Rate of Cognitive Decline in Very Old Adults. J Nutr. 2016. 146:265-74. doi:10.3945/jn.115.216952 
25 Hardman, RJ, Meyer, D, Kennedy, G, Macpherson, H, Scholey, AB, Pipingas, A. The association between adherence to a Mediterranean style diet and cognition in older people: The impact of medication. Clin Nutr. 2018. 37:2156-2165. doi:10.1016/j.clnu.2017.10.015

26 Hill, E, Clifton, P, Goodwill, AM, Dennerstein, L, Campbell, S, Szoeke, C. Dietary patterns and beta-amyloid deposition in aging Australian women. Alzheimers Dement (N Y). 2018. 4:535-541. doi:10.1016/j.trci.2018.09.007

27 Hosking, DE, Nettelbeck, T, Wilson, C, Danthiir, V. Retrospective lifetime dietary patterns predict cognitive performance in community-dwelling older Australians. Br J Nutr. 2014. 112:228-37. doi:10.1017/s0007114514000646

28 Kesse-Guyot, E, Andreeva, VA, Ducros, V, Jeandel, C, Julia, C, Hercberg, S, Galan, P. Carotenoid-rich dietary patterns during midlife and subsequent cognitive function. Br J Nutr. 2014. 111:915-23. doi:10.1017/s0007114513003188

29 Lee, J, Pase, M, Pipingas, A, Raubenheimer, J, Thurgood, M, Villalon, L, Macpherson, H, Gibbs, A, Scholey, A. Switching to a 10day Mediterranean-style diet improves mood and cardiovascular function in a controlled crossover study. Nutrition. 2015. 31:64752. doi:10.1016/j.nut.2014.10.008

30 Lehtisalo, J, Levalahti, E, Lindstrom, J, Hanninen, T, Paajanen, T, Peltonen, M, Antikainen, R, Laatikainen, T, Strandberg, T, Soininen, $\mathrm{H}$, et al. Dietary changes and cognition over 2 years within a multidomain intervention trial-The Finnish Geriatric Intervention Study to Prevent Cognitive Impairment and Disability (FINGER). Alzheimer's \& dementia. 2019. 15:410-417. doi:10.1016/j.jalz.2018.10.001

31 Lehtisalo, J, Levalahti, E, Lindstrom, J, Hanninen, T, Paajanen, T, Peltonen, M, Antikainen, R, Laatikainen, T, Strandberg, T, Soininen, H, Tuomilehto, J, Kivipelto, M, Ngandu, T. Dietary changes and cognition over 2 years within a multidomain intervention trial-The Finnish Geriatric Intervention Study to Prevent Cognitive Impairment and Disability (FINGER). Alzheimers Dement. 2019. 15:410-417. doi:10.1016/j.jalz.2018.10.001

$32 \mathrm{Li}, \mathrm{J}$, Ogrodnik, M, Kolachalama, VB, Lin, H, Au, R. Assessment of the Mid-Life Demographic and Lifestyle Risk Factors of Dementia Using Data from the Framingham Heart Study Offspring Cohort. Journal of Alzheimer's Disease. 2018. 63:1119-1127. doi:10.3233/JAD-170917

33 Lutski, M, Weinstein, G, Ben-Zvi, S, Goldbourt, U, Tanne, D. Adherence to Mediterranean diet and subsequent cognitive decline in men with cardiovascular disease. Nutr Neurosci. 2020. 1-9. doi:10.1080/1028415x.2020.1715049

34 Matthews, DC, Davies, M, Murray, J, Williams, S, Tsui, WH, Li, Y, Andrews, RD, Lukic, A, McHugh, P, Vallabhajosula, S, de Leon, MJ, Mosconi, L. Physical Activity, Mediterranean Diet and Biomarkers-Assessed Risk of Alzheimer's: A Multi-Modality Brain Imaging Study. Adv J Mol Imaging. 2014. 4:43-57. doi:10.4236/ami.2014.44006

35 Mazza, E, Fava, A, Ferro, Y, Moraca, M, Rotundo, S, Colica, C, Provenzano, F, Terracciano, R, Greco, M, Foti, D, Gulletta, E, Russo, D, Bosco, D, Pujia, A, Montalcini, T. Impact of legumes and plant proteins consumption on cognitive performances in the elderly. J Transl Med. 2017. 15:109. doi:10.1186/s12967-017-1209-5

36 Milte, CM, Ball, K, Crawford, D, McNaughton, SA. Diet quality and cognitive function in mid-aged and older men and women. BMC Power/Size Geriatr. 2019. 19:361. doi:10.1186/s12877-019-1326-5 
37 Mohorko, N, Cernelic-Bizjak, M, Poklar-Vatovec, T, Grom, G, Kenig, S, Petelin, A, Jenko-Praznikar, Z. Weight loss, improved physical performance, cognitive function, eating behavior, and metabolic profile in a 12-week ketogenic diet in obese adults. Nutr Res. 2019. 62:64-77. doi:10.1016/j.nutres.2018.11.007

38 Morris, MC, Tangney, CC, Wang, Y, Sacks, FM, Barnes, LL, Bennett, DA, Aggarwal, NT. MIND diet slows cognitive decline with aging. Alzheimers Dement. 2015. 11:1015-22. doi:10.1016/j.jalz.2015.04.011

39 Morris, MC, Tangney, CC, Wang, Y, Sacks, FM, Bennett, DA, Aggarwal, NT. MIND diet associated with reduced incidence of Alzheimer's disease. Alzheimers Dement. 2015. 11:1007-14. doi:10.1016/j.jalz.2014.11.009

40 Munoz-Garcia, MI, Toledo, E, Razquin, C, Dominguez, LJ, Maragarone, D, Martinez-Gonzalez, J, Martinez-Gonzalez, MA. "A priori" Dietary Patterns and Cognitive Function in the SUN Project. Neuroepidemiology. 2020. 54:45-57. doi:10.1159/000502608

41 Olsson, E, Karlstrom, B, Kilander, L, Byberg, L, Cederholm, T, Sjogren, P. Dietary patterns and cognitive dysfunction in a 12-year follow-up study of 70 year old men. J Alzheimers Dis. 2015. 43:109-19. doi:10.3233/jad-140867

42 Panza, F, Solfrizzi, V, Giannini, M, Seripa, D, Pilotto, A, Logroscino, G. Nutrition, frailty, and Alzheimer's disease. Frontiers in Aging Neuroscience. 2014. 6. doi:10.3389/fnagi.2014.00221

43 Park, JE, Jeon, SY, Kim, SA, Kim, JH, Kim, SH, Lee, KW, Hwang, YJ, Jung, G, Suk, HW, Park, S, Lee, DY. A Multidomain Intervention for Modifying Lifestyle Habits Reduces the Dementia Risk in Community-Dwelling Older Adults: A Single-Blinded Randomized Controlled Pilot Study. J Alzheimers Dis. 2019. 70:51-60. doi:10.3233/jad-190016

44 Pelletier, A, Barul, C, Feart, C, Helmer, C, Bernard, C, Periot, O, Dilharreguy, B, Dartigues, JF, Allard, M, Barberger-Gateau, P, Catheline, G, Samieri, C. Mediterranean diet and preserved brain structural connectivity in older subjects. Alzheimers Dement. 2015. 11:1023-31. doi:10.1016/j.jalz.2015.06.1888

45 Perrone, L, Grant, WB. Observational and ecological studies of dietary advanced glycation end products in national diets and Alzheimer's disease incidence and prevalence. J Alzheimers Dis. 2015. 45:965-79. doi:10.3233/jad-140720

46 Prinelli, F, Fratiglioni, L, Musicco, M, Johansson, I, Adorni, F, Shakersain, B, Rizzuto, D, Xu, W. The impact of nutrient-based dietary patterns on cognitive decline in older adults. Clin Nutr. 2019. 38:2813-2820. doi:10.1016/j.clnu.2018.12.012

47 Qin, B, Adair, LS, Plassman, BL, Batis, C, Edwards, LJ, Popkin, BM, Mendez, MA. Dietary Patterns and Cognitive Decline Among Chinese Older Adults. Epidemiology. 2015. 26:758-68. doi:10.1097/ede.0000000000000338

48 Rainey-Smith, SR, Gu, Y, Gardener, SL, Doecke, JD, Villemagne, VL, Brown, BM, Taddei, K, Laws, SM, Sohrabi, HR, Weinborn, M, Ames, D, Fowler, C, Macaulay, SL, Maruff, P, Masters, CL, Salvado, O, Rowe, CC, Scarmeas, N, Martins, RN. Mediterranean diet adherence and rate of cerebral Abeta-amyloid accumulation: Data from the Australian Imaging, Biomarkers and Lifestyle Study of Ageing. Transl Psychiatry. 2018. 8:238. doi:10.1038/s41398-018-0293-5

49 Seetharaman, S, Andel, R, McEvoy, C, Dahl Aslan, AK, Finkel, D, Pedersen, NL. Blood glucose, diet-based glycemic load and cognitive aging among dementia-free older adults. J Gerontol A Biol Sci Med Sci. 2015. 70:471-9. doi:10.1093/gerona/glu135

50 Tanaka, T, Talegawkar, SA, Jin, Y, Colpo, M, Ferrucci, L, Bandinelli, S. Adherence to a Mediterranean Diet Protects from Cognitive Decline in the Invecchiare in Chianti Study of Aging. Nutrients. 2018. 10. doi:10.3390/nu10122007

Study Design, Intervention/

Exposure

Power/Size

Power/Size

Power/Size

Power/Size

Study Design

Intervention/

Exposure

Outcome

Study Design

Intervention/

Exposure

Country

Outcome

Power/Size

Power/Size 
51 Tangney, CC, Li, H, Wang, Y, Barnes, L, Schneider, JA, Bennett, DA, Morris, MC. Relation of DASH- and Mediterranean-like dietary patterns to cognitive decline in older persons. Neurology. 2014. 83:1410-6. doi:10.1212/wnl.0000000000000884

52 Trichopoulou, A, Kyrozis, A, Rossi, M, Katsoulis, M, Trichopoulos, D, La Vecchia, C, Lagiou, P. Mediterranean diet and cognitive Power/Size decline over time in an elderly Mediterranean population. Eur J Nutr. 2015. 54:1311-21. doi:10.1007/s00394-014-0811-z

53 Tsai, HJ. Dietary patterns and cognitive decline in Taiwanese aged 65 years and older. Int J Geriatr Psychiatry. 2015. 30:523-30. Country doi:10.1002/gps.4176

54 Wade, AT, Davis, CR, Dyer, KA, Hodgson, JM, Woodman, RJ, Keage, HAD, Murphy, KJ. A Mediterranean diet supplemented with dairy foods improves mood and processing speed in an Australian sample: results from the MedDairy randomized controlled trial. Nutr Neurosci. 2018:1-13. doi:10.1080/1028415x.2018.1543148

55 Wade, AT, Davis, CR, Dyer, KA, Hodgson, JM, Woodman, RJ, Keage, HAD, Murphy, KJ. A Mediterranean Diet with Fresh, Lean Pork Improves Processing Speed and Mood: Cognitive Findings from the MedPork Randomised Controlled Trial. Nutrients. 2019. 11. doi:10.3390/nu11071521

56 Wade, AT, Elias, MF, Murphy, KJ. Adherence to a Mediterranean diet is associated with cognitive function in an older nonMediterranean sample: findings from the Maine-Syracuse Longitudinal Study. Nutr Neurosci. 2019. 1-12. doi:10.1080/1028415x.2019.1655201

$57 \mathrm{Yu}, \mathrm{FN}, \mathrm{Hu}, \mathrm{NQ}$, Huang, XL, Shi, YX, Zhao, HZ, Cheng, HY. Dietary patterns derived by factor analysis are associated with cognitive function among a middle-aged and elder Chinese population. Psychiatry Res. 2018. 269:640-645. doi:10.1016/j.psychres.2018.09.004

58 Yuan, L, Liu, J, Ma, W, Dong, L, Wang, W, Che, R, Xiao, R. Dietary pattern and antioxidants in plasma and erythrocyte in patients with mild cognitive impairment from China. Nutrition. 2016. 32:193-8. doi:10.1016/j.nut.2015.08.004

59 Zbeida, M, Goldsmith, R, Shimony, T, Vardi, H, Naggan, L, Shahar, DR. Mediterranean diet and functional indicators among older adults in non-Mediterranean and Mediterranean countries. J Nutr Health Aging. 2014. 18:411-8. doi:10.1007/s12603-014-0003-9

60 Zhao, X, Yuan, L, Feng, L, Xi, Y, Yu, H, Ma, W, Zhang, D, Xiao, R. Association of dietary intake and lifestyle pattern with mild cognitive impairment in the elderly. J Nutr Health Aging. 2015. 19:164-8. doi:10.1007/s12603-014-0524-2 